\title{
The Importance of Hiring Frictions in Business Cycles
}

\author{
Renato Faccini \\ Queen Mary, University of London, and CfM, London School of Economics* \\ Eran Yashiv \\ Tel Aviv University, CfM, London School of Economics, and CEPR ${ }^{\dagger}$
}

November 17, 2017 $\ddagger$

\begin{abstract}
The paper shows that there is an important direct role for hiring frictions in business cycles. This runs counter to key models in several strands of the macroeconomic literature, which imply that hiring frictions are not important per-se.

In our model, conventional shocks yield non-standard and non-obvious macroeconomic outcomes in the presence of hiring frictions. Specifically, hiring frictions operate to offset, and possibly reverse, the effects of price frictions. This confluence of frictions has substantial effects. For a sub-set of the parameter space, model outcomes appear "frictionless," though both hiring frictions and price frictions are at play. For a different sub-space, these interactions between the two frictions generate amplification in the responses of employment and unemployment to technology shocks, rather than friction-induced mitigation of responses. Despite the presence of price rigidity, positive technology shocks may still be expansionary in employment, and the effects of monetary policy shocks may still be negligible.

We explain the underlying economic mechanisms and show their empirical implementation. In doing so, we argue in favor of the importance of explicitly using hiring frictions in business cycle modelling.
\end{abstract}

Keywords: hiring frictions; business cycles; interactions with price frictions; endogenous wage rigidity.

JEL codes: E22, E24, E32, E52

\footnotetext{
*Email: r.faccini@qmul.ac.uk

${ }^{\dagger}$ Email: yashiv@post.tau.ac.il; e.yashiv@lse.ac.uk

$\ddagger$ We are grateful to Bjorn Brugemann, Jordi Gali, Pieter Gautier, Marc Giannoni, Leonardo Melosi, Guido Menzio, Giuseppe Moscarini, Karl Walentin, and Michael Woodford for very useful feedback and suggestions on previous versions. We have received valuable comments from seminar participants at the 2017 NBER Summer Institute, Columbia, the NY Fed, CREI, LSE, EUI, Riksbank, the Bank of England, Stockholm School of Economics, Tel Aviv, the 2017 SED conference in Edinburgh and the 2016 search conference in Sandbjerg. We thank Tanya Baron, Avihai Lifschitz, and Andrey Perlin for research assistance. Any errors are our own. The graphs in this paper are best viewed in color.
} 


\section{Non-Technical Summary}

Is there a direct role for hiring frictions in business cycles and are they important? Can they explain volatile labor market outcomes? This paper suggests that the answer to these questions is positive. This view runs counter to key models in major strands of the macroeconomic literature, which give negative answers.

Labor market frictions in the tradition of Diamond, Mortensen, and Pissarides, have been found to play a negligible direct role in explaining business cycle fluctuations. In a survey of the literature, Rogerson and Shimer (2011) conclude that, by acting like a labor adjustment cost, search frictions dampen the volatility of employment. If anything then, they exacerbate the difficulties of the frictionless New-Classical paradigm to account for the cyclical behavior of the labor market. These models typically abstract from price frictions, emphasized by the canonical New Keynesian approach.

When labor market frictions, as modelled in Diamond, Mortensen, and Pissarides, have been explicitly incorporated within New Keynesian models, they still do not contribute directly to the explanation of business cycles. In particular, the propagation of shocks is virtually unaffected by the presence of these frictions (see Gali (2011)). Frictions in the labor market have been found to be important, but only indirectly. They create a match surplus, allowing for privately efficient wage setting that involves wage stickiness, which, in turn, has business cycle implications.

The contribution of this paper is to show that there is a direct role of hiring frictions in business cycle dynamics. Hence, hiring frictions matter per se, and not just because they allow for privately efficient wage rigidity. We begin by presenting a simple model of the business cycle that includes price frictions. We show that in this set-up conventional shocks yield non-standard and non-obvious macroeconomic outcomes in the presence of hiring frictions. Namely, we find that hiring frictions are an important source of propagation and amplification of technology shocks, that they play a key role in the transmission of monetary policy shocks, and that they generate endogenous wage rigidity. Hiring frictions are shown to overturn some mechanisms that have received much attention in the literature. Thus, for a sub-set of the parameter space, positive technology shocks may still be expansionary in employment, and monetary policy shocks may still have negligible effects, in line with the predictions of new classical models, and despite price rigidity.

Our model relies on two essential ingredients, for which there is strong empirical macroand micro-based evidence. The first is the explicit modelling of internal costs of hiring, such as training costs. These are different from the canonical vacancy posting costs, which depend on external market conditions. We show that the latter costs can be included in the model but cannot be the exclusive source of frictions. The second key ingredient is that hiring costs are output costs, that is, they entail disruption to production.

Our model reproduces two well-known results as special cases: first, the result obtained in the Diamond-Mortensen-Pissarides literature, whereby hiring frictions operate as adjustment costs, implying that they mitigate responses, hence precluding any significant effects of fric- 
tions in explaining volatile labor market variables. But this result only arises in the special case where price frictions are shut down or restricted to be quantitatively negligible. Second, we also show that our model can recover the result obtained in the New-Keynesian literature, whereby hiring frictions do not matter much, per se. But this result only arises in the special case where hiring costs derive only from vacancies or, more generally, whenever internal hiring costs are assumed to be implausibly small. As we depart from these knife-edge assumptions, the interaction of price frictions and hiring frictions produces a host of interesting results.

The intuition for the mechanism is as follows. Consider an expansionary TFP shock, which increases productivity and, everything else equal, output supply. If prices are sticky, they cannot drop and stimulate aggregate demand enough to restore equilibrium in the output market. This generates excess supply. In the textbook New Keynesian model, employment unambiguously falls to clear the market. In our model instead, excess capacity entails a fall in the marginal cost of hiring. Indeed, because hiring costs are modelled as forgone output, hiring entails an opportunity cost of production, which falls as a result of excess capacity. Hence, firms have an incentive to increase hiring and employment, as the existing workforce is used to train new workers. In equilibrium, employment may rise if the fall in marginal hiring costs is sufficiently strong.

Now consider an expansionary monetary policy shock. This induces excess output demand, as prices do not increase enough to clear the market. In the textbook New Keynesian model, employment unambiguously increases to restore the equilibrium. In our model instead, excess demand entails an increase in marginal hiring costs, which are an opportunity cost of production. This increase in the cost of hiring offsets the initial incentive to raise employment. In equilibrium, hiring may increase or fall, depending on how strong is the response of the cost of hiring. Ultimately, the endogenous response of hiring costs to the underlying shocks operates so as to offset, and possibly reverse the standard New Keynesian propagation. We show that the sensitivity of marginal hiring costs to both technology and monetary policy shocks is proportional to the value of a job to the firm.

While the empirical literature on price frictions has reached a relatively mature stage of development, empirical work that tries to measure hiring frictions is still relatively scant. Much more work is needed for business cycle models to confidently rely on a specific calibration. In this paper we inspect how the transmission of shocks yields different outcomes allowing for both hiring frictions and price frictions, using a grid of plausible parameterizations. This analysis illustrates how hiring frictions matter for the transmission of shocks in business cycle models. Specifically, hiring frictions are just as important as price frictions for the propagation of shocks in New Keynesian models. At the same time, the macro modelling of labor market dynamics needs to recognize the important role played by price frictions in its interaction with hiring frictions. This interaction, or confluence of frictions, is key. 


\section{Introduction}

Is there a direct role for hiring frictions in business cycles and are they important? Can they explain volatile labor market outcomes? This paper suggests that the answer to these questions is positive. This view runs counter to key models in major strands of the macroeconomic literature, which give negative answers.

Consider two benchmark literatures as a point of departure. First, labor market frictions in the tradition of Diamond, Mortensen, and Pissarides, have been found to play a negligible direct role in explaining business cycle fluctuations. In a survey of the literature, Rogerson and Shimer (2011) conclude that, by acting like a labor adjustment cost, search frictions dampen the volatility of employment. If anything then, they exacerbate the difficulties of the frictionless New-Classical paradigm to account for the cyclical behavior of the labor market. These models typically abstract from price frictions, emphasized by the canonical New Keynesian approach.

Second, when labor market frictions, as modelled in Diamond, Mortensen, and Pissarides, have been explicitly incorporated within New Keynesian models, they still do not contribute directly to the explanation of business cycles. In particular, the propagation of shocks is virtually unaffected by the presence of these frictions (see Galí (2011)). Frictions in the labor market have been found to be important, but only indirectly. They create a match surplus, allowing for privately efficient wage setting that involves wage stickiness, which, in turn, has business cycle implications. A prominent recent contribution to this type of analysis is Christiano, Eichenbaum, and Trabandt (2016). These authors use a wage bargaining protocol in the presence of hiring frictions to generate endogenous wage rigidity, with significant cyclical implications.

The contribution of this paper is to show that there is a direct role of hiring frictions in business cycle dynamics. Hence, hiring frictions matter per se, and not just because they allow for privately efficient wage rigidity. We begin by presenting a simple model of the business cycle that includes price frictions. We show that in this set-up conventional shocks yield non-standard and non-obvious macroeconomic outcomes in the presence of hiring frictions. Namely, we find that hiring frictions are an important source of propagation and amplification of technology shocks, that they play a key role in the transmission of monetary policy shocks, and that they generate endogenous wage rigidity. Hiring frictions are shown to overturn some mechanisms that have received much attention in the literature. Thus, for a sub-set of the parameter space, positive technology shocks may still be expansionary in employment, and monetary policy shocks may still have negligible effects, in line with the predictions of new classical models, and despite price rigidity.

The framework used allows us to explore the underlying mechanisms. Subsequently, we explore the robustness of our results in a larger scale DSGE model, augmented with various features that are prevalent in the literature. Notably, the model of this paper encompasses key formulations in the business cycle literature as special cases.

Our model relies on two essential ingredients, for which there is strong empirical macroand micro-based evidence. The first is the explicit modelling of internal costs of hiring, such as training costs. These are different from the canonical vacancy posting costs, which depend 
on external market conditions. We show that the latter costs can be included in the model but cannot be the exclusive source of frictions. The second key ingredient is that hiring costs are output costs, that is, they entail disruption to production. We review this modelling of hiring frictions in the context of the relevant literature in sub-section 2.2 below. Here we simply note that papers in the literature either have made none of these two assumptions, or when they assumed the first, they did not also assume the second.

Our model reproduces two well-known results as special cases: first, the result obtained in the Diamond-Mortensen-Pissarides literature, whereby hiring frictions operate as adjustment costs, implying that they mitigate responses, hence precluding any significant effects of frictions in explaining volatile labor market variables. But this result only arises in the special case where price frictions are shut down or restricted to be quantitatively negligible. Second, we also show that our model can recover the result obtained in the New-Keynesian literature, whereby hiring frictions do not matter much, per se. But this result only arises in the special case where hiring costs derive only from vacancies or, more generally, whenever internal hiring costs are assumed to be implausibly small. As we depart from these knife-edge assumptions, the interaction of price frictions and hiring frictions produces a host of interesting results.

The intuition for the mechanism is as follows. Consider an expansionary TFP shock, which increases productivity and, everything else equal, output supply. If prices are sticky, they cannot drop and stimulate aggregate demand enough to restore equilibrium in the output market. This generates excess supply. In the textbook New Keynesian model, employment unambiguously falls to clear the market. In our model instead, excess capacity entails a fall in the marginal cost of hiring. Indeed, because hiring costs are modelled as forgone output, hiring entails an opportunity cost of production, which falls as a result of excess capacity. Hence, firms have an incentive to increase hiring and employment, as the existing workforce is used to train new workers. In equilibrium, employment may rise if the fall in marginal hiring costs is sufficiently strong.

Now consider an expansionary monetary policy shock. This induces excess output demand, as prices do not increase enough to clear the market. In the textbook New Keynesian model, employment unambiguously increases to restore the equilibrium. In our model instead, excess demand entails an increase in marginal hiring costs, which are an opportunity cost of production. This increase in the cost of hiring offsets the initial incentive to raise employment. In equilibrium, hiring may increase or fall, depending on how strong is the response of the cost of hiring. Ultimately, the endogenous response of hiring costs to the underlying shocks operates so as to offset, and possibly reverse the standard New Keynesian propagation. We show that the sensitivity of marginal hiring costs to both technology and monetary policy shocks is proportional to the value of a job to the firm.

In a survey paper, Ramey (2016) summarizes the contradictory empirical evidence in the literature on the propagation of technology and monetary policy shocks. Our model is able to account for the mix of findings. Different results can be supported by a different combination of price and hiring frictions. Notably, Ramey (2016) finds that adopting a variety of agnostic identification schemes in monetary VARs, which relax the assumption that output 
and inflation cannot respond contemporaneously to monetary policy, leads to "puzzling" results, whereby industrial production significantly increases and unemployment decreases for a few quarters after a monetary policy contraction. Similarly, the empirical evidence presented by Nekarda and Ramey (2013) on mark-ups being pro-cyclical conditional on monetary policy shocks, also appears as a "puzzle", when interpreted within the confines of a textbook NewKeynesian model. Yet even these results, would not appear "puzzling" when seen through the lenses of our model. Indeed, they can be supported by a combination of sufficiently strong, yet plausible, hiring and price frictions.

While the empirical literature on price frictions has reached a relatively mature stage of development, empirical work that tries to measure hiring frictions is still relatively scant. This lacuna is all the more striking given the extensive empirical work on gross hiring flows (and other worker flows) by Davis and Haltiwanger and co-authors. ${ }^{1}$ Much more work is needed for business cycle models to confidently rely on a specific calibration. In this paper we inspect how the transmission of shocks yields different outcomes allowing for both hiring frictions and price frictions, using a grid of plausible parameterizations. This analysis illustrates how hiring frictions matter for the transmission of shocks in business cycle models. Specifically, hiring frictions are just as important as price frictions for the propagation of shocks in New Keynesian models. At the same time, the macro modelling of labor market dynamics needs to recognize the important role played by price frictions in its interaction with hiring frictions. This interaction, or confluence of frictions, is key.

The paper is organized as follows. Section 2 reviews the related literature, placing the paper in its relevant context. Section 3 presents the baseline model with a minimal set of assumptions. We explain the mechanism by empirically implementing this model: Section 4 discusses calibration and presents impulse responses. Section 5 is then able to investigate the interaction of price and hiring frictions for a grid of parameter values and to explain the mechanisms. Section 6 explores the robustness of the mechanisms to the use of a richer macroeconomic DSGE model, including the introduction of different forms of hiring frictions and different parameterizations of the Taylor rule. Section 7 concludes. Technical matters are relegated to appendices.

\section{Relation to the Existing Literature}

To place this paper in context and explain its contribution, we briefly survey the relevant strands in the literature. In what follows, we denote the New Classical model by NC, the New Keynesian model by NK, and the Diamond, Mortensen and Pissarides model by DMP. We examine two strands: those papers which investigate the role of hiring frictions in business cycle dynamics, and those that provide evidence on the nature of hiring costs.

\footnotetext{
${ }^{1}$ Starting from their early work, Davis, Haltiwanger and Schuh (1996) and Davis and Haltiwanger (1999), and going up to the recent contribution in Davis and Haltiwanger (2014).
} 


\subsection{Hiring Frictions and Business Cycles}

The use of labor market frictions in general equilibrium, business cycle settings yielded mixed results. At first, Merz (1995), Andolfatto (1996), and Den Haan, Ramey and Watson (2000) found the DMP model enhances the performance of the NC model. But Shimer (2005) offered a strong critique of its usefulness, arguing that for realistic productivity shocks, the standard DMP model fails to generate the unemployment and vacancy volatility found in the data. The paper spawned a large body of work on this "Shimer puzzle." Rogerson and Shimer (2011) argued that in the business cycle context, the main substantive contribution of search models is the presence of match specific rents and hence the opportunity for a richer set of wage setting processes. Yet, relative to a frictionless counterpart, search frictions do not help generate volatility or persistence per se. Rather, by acting like a labor adjustment cost, search frictions dampen the volatility of employment. If anything then, they exacerbate the difficulties of the frictionless neoclassical paradigm to account for the cyclical behavior of the labor market.

An important strand in the business cycle literature has embedded labor market frictions in NK models. Prominent contributions include Walsh (2005), Krause, Lopez-Salido and Lubik (2008), Gertler, Sala, and Trigari (2008), Galí (2011), and Christiano, Eichenbaum and Trabandt (2016). Most of these papers, too, found little, if any, direct effect of hiring costs. For example, Krause, Lopez-Salido and Lubik (2008) state that the contribution of labor market frictions to inflation dynamics is small. Galí (2011) showed that labor market frictions per se matter little for the outcomes of macroeconomic variables, and in particular aggregate labor market variables. The role of these frictions, he finds, is to reconcile the presence of wage rigidities with privately efficient employment relations. ${ }^{2}$ Gertler, Sala, and Trigari (2008) estimate a medium-scale macroeconomic model with DMP frictions and staggered nominal wage contracting. Their main findings about the fit of the model to U.S. data do not pertain to the frictions per se but to the inherent wage rigidity, which delivers better results than a model with flexible wages. Christiano, Eichenbaum, and Trabandt (2016), too, get meaningful effects via the wage setting mechanism. In their NK model with labor market frictions, an alternatingoffer bargaining set-up generates endogenous wage rigidity. This facilitates explanations of all key macroeconomic variables.

Our paper provides for very different mechanisms, with the key one ensuing from the setup of gross hiring costs in the form of lost output.

\subsection{The Modelling of Hiring Frictions}

The literature postulates different formulations for hiring frictions. Here we briefly review them, to place our modelling into context. Three distinctions regarding the hiring cost function matter for the current paper. One relates to the arguments - are the costs related to actual hires, or related to aggregate labor market conditions, such as vacancy filling rates? A second is whether these costs are pecuniary costs paid to other firms for the provision of hiring services,

\footnotetext{
${ }^{2}$ Thus models with labor frictions and the associated wage setting mechanisms satisfy the Barro (1977) criterion, whereby in a rational wage setting equilibrium, bi-lateral private efficiency should prevail.
} 
or rather production costs entailing a loss of output within the firm. A third pertains to the shape of the function.

The traditional DMP literature relates to vacancy costs, in the form of pecuniary costs, and modelled as linear costs. This formulation was conceived for simplicity and tractability in a theoretical framework, such as the one presented in Pissarides (2000). It was not based on empirical evidence or formulated to make an empirical statement. In particular, it is part of a model that has a one worker-one firm set up. In this formulation, there is no meaning for costs rising in the hiring rate. If there were no effects of market conditions via the job filling rate, the optimal hiring condition would lack an endogenous variable relating to hiring.

External costs vs. internal costs. Vacancy costs have been referred to as external costs of hiring as they depend on aggregate labor market conditions, for example, the ratio of aggregate vacancies to aggregate job seekers. Costs of actual hires have been defined in the literature as internal costs as they depend on firm-level conditions, namely the ratio of new hires to the workforce of the firm, i.e. the gross hiring rate. The underlying idea is that internal costs consist of training costs, including the time costs associated with learning how to operate capital, as well as the costs incurred in the implementation of new organizational structures within the firm and new production techniques; for the latter, see Alexopoulos (2011) and Alexopoulos and Tombe (2012). Unlike the afore-cited traditional linear vacancy costs, a host of papers has estimated and/or used actual hiring costs. See, for example, Yashiv (2000), Merz and Yashiv (2007), Gertler, Sala, and Trigari (2008), Pissarides (2009), Christiano, Trabandt and Walentin (2011), Sala, Soderstrom, and Trigari (2013), Yashiv (2016), Furlanetto and Groeshny (2016), Coles and Mortensen (2016), and Christiano, Eichenbaum and Trabandt (2016). Christiano, Trabandt, and Walentin (2011), using Bayesian estimation of a DSGE model of Sweden, conclude that "employment adjustment costs are a function of hiring rates, not vacancy posting rates." Sala, Soderstrom, and Trigari (2012) estimate external and internal costs for a number of countries including the US, the UK, Sweden and Germany. With the exception of Germany, internal costs account for most of the costs of hiring. These macro estimates align well with micro estimates suggesting that internal costs are far more important than external costs both in the US and in other countries; see Silva and Toledo (2009, Table 1) and Blatter et al (2016, Table 1). In our modelling, we follow these results. Quantitatively, moving away from the vacancy cost formulation allows us to inspect the effects of hiring costs under a broader spectrum of parameterizations. But while our benchmark model has costs relating only to the gross hiring rate, in Section 6 below we look at a broader specification, which encompasses also external vacancy costs.

Pecuniary costs paid to other agents vs output costs. In much of the literature, hiring costs are expressed in units of the final good, and contribute to aggregate GDP (see, among many others, Gertler Sala and Trigari (2008), Galí (2011), Christiano Eichenbaum and Trabandt (2016)). As such, these cost can be interpreted as pecuniary payments to other firms for the provision of hiring services. However, evidence reviewed by Silva and Toledo (2009) and Blatter (2016) provides little indication of hiring activities being outsourced to other firms or hiring costs 
being recorded in accounting books as third-party payments. ${ }^{3}$ Rather, they provide evidence that most of the cost of hiring is incurred within the firm, and is measured as the opportunity cost of work incurred by co-workers, managers and the new hires themselves, in connection with recruitment or training activities. In this paper we model hiring costs accordingly, that is, as an opportunity cost of production. This implies that in our model aggregate hiring costs take away from GDP rather than add to GDP. In Section 6 below we explore the implications of replacing output costs by pecuniary costs.

Functional form. Those cited papers which have used structural estimation (Yashiv (2000, 2016, 2017), Merz and Yashiv (2007), and Christiano, Trabandt, and Walentin (2011)) point to convex formulations as fitting the data better than linear ones. ${ }^{4}$ One can also rely on the theoretical justifications of King and Thomas (2006) and Khan and Thomas (2008) for convexity. Note, though, that for the mechanism delineated above and explored below to operate qualitatively the precise degree of convexity in costs does not matter.

This convex, output costs approach naturally links the hiring problem with a strand of the Macro-Finance literature on firms investment and/or hiring decisions and their linkages to financial markets. See Cochrane (2005, Chapter 20, and 2008) for overviews and discussions.

\section{The Model}

The model features two frictions: price adjustment costs and costs of hiring workers. Absent both frictions, the model boils down to the benchmark NC model with labor and capital. Following the Real Business Cycle tradition, capital is included because it plays a key role in producing a positive response of employment to productivity shocks. ${ }^{5}$

Introducing price frictions into the otherwise frictionless model yields the NK benchmark, and introducing hiring frictions into the NK benchmark allows us to analyze how the interplay between these frictions affects the propagation of technology and monetary policy shocks. In this section, and in order to focus on the above interplay, our modeling strategy deliberately abstracts from all other frictions and features that are prevalent in DSGE models and which are typically introduced to enhance propagation and improve statistical fit, namely, habits in consumption, investment adjustment costs, exogenous wage rigidities, etc. In Section 6 below we examine the robustness of our results with respect to such modifications.

In what follows we look in detail at households and firms, the labor market, the monetary and fiscal authorities, and the aggregate economy.

\footnotetext{
${ }^{3}$ Blatter et al. (2016) provide evidence of some expenses being incurred for external advisors/headhunters. Overall they account for a very small part of total hiring costs.

${ }^{4}$ Blatter et al (2016, page 4) offer citations of additional studies indicating convexity of hiring costs.

${ }^{5}$ With standard logarithmic preferences over consumption and labor as the only input of production, income and substitution effects cancel out and a NC model with or without hiring frictions would not produce any change in employment or unemployment to productivity shocks (see Blanchard and Gali (2010)).
} 


\subsection{Households}

The representative household comprises a unit measure of workers who, at the end of each time period, can be either employed or unemployed: $N_{t}+U_{t}=1$. We therefore abstract from participation decisions and from variation of hours worked on the intensive margin. ${ }^{6}$ The household enjoys utility from the aggregate consumption index $C_{t}$, reflecting the assumption of full-consumption sharing among the household's members. In addition, the household derives disutility from the fraction of household members who are employed, $N_{t}$. It can save by either purchasing zero-coupon government bonds, at the discounted value $\frac{B_{t+1}}{R_{t}}$, or by investing in physical capital, $K_{t}$. The latter evolves according to the law of motion:

$$
K_{t}=\left(1-\delta_{K}\right) K_{t-1}+I_{t}, \quad 0<\delta_{K}<1,
$$

where it is assumed that the existing capital stock depreciates at the rate $\delta_{K}$ and is augmented by new investment $I_{t}$. We further assume that both consumption and investment are purchases of the same composite good, which has price $P_{t}$. The household earns nominal wages $W_{t}$ from the workers employed, and receives nominal proceeds $R_{t}^{K} K_{t-1}$ from renting physical capital to the firms. The budget constraint is:

$$
P_{t} C_{t}+P_{t} I_{t}+\frac{B_{t+1}}{R_{t}}=W_{t} N_{t}+R_{t}^{K} K_{t-1}+B_{t}+\Omega_{t}-T_{t}
$$

where $R_{t}=\left(1+i_{t}\right)$ is the gross nominal interest rate on bonds, $\Omega_{t}$ denotes dividends from ownership of firms and $T_{t}$ lump sum taxes.

The labor market is frictional and workers who are unemployed at the beginning of the period are denoted by $U_{t}^{0}$. It is assumed that these workers can start working in the same period if they find a job with probability $x_{t}=\frac{H_{t}}{U_{t}^{0}}$, where $H_{t}$ denotes the total number of new hires. It follows that the workers who remain unemployed for the rest of the period, denoted by $U_{t}$, is $U_{t}=\left(1-x_{t}\right) U_{t}^{0}$. Consequently, the evolution of aggregate employment $N_{t}$ is:

$$
N_{t}=\left(1-\delta_{N}\right) N_{t-1}+x_{t} U_{t}^{0}
$$

where $\delta_{N}$ is the separation rate.

The intertemporal problem of the households is to maximize the discounted present value of current and future utility:

$$
\max _{\left\{C_{t+j}, I_{t+j}, B_{t+j+1}\right\}_{j=0}^{\infty}} E_{t} \sum_{j=0}^{\infty} \beta^{j}\left(\ln C_{t+j}-\frac{\chi}{1+\varphi} N_{t+j}^{1+\varphi}\right),
$$

subject to the budget constraint (2), and the laws of motion for employment, in eq.(3), and capital, in eq.(1). The parameter $\beta \in(0,1)$ denotes the discount factor, $\varphi$ is the inverse Frisch elasticity of labor supply, and $\chi$ is a scale parameter governing the disutility of work.

\footnotetext{
${ }^{6}$ As shown in Rogerson and Shimer (2011), most of the fluctuations in US total hours worked at business cycle frequencies are driven by the extensive margin, so our model deliberately abstracts from other margins of variation.
} 
The solution to the intertemporal problem of the household yields the standard Euler equation:

$$
\frac{1}{R_{t}}=\beta E_{t} \frac{P_{t} C_{t}}{P_{t+1} C_{t+1}}
$$

an equation characterizing optimal investment decisions:

$$
1=E_{t} \Lambda_{t, t+1}\left[\frac{R_{t+1}^{K}}{P_{t+1}}+\left(1-\delta_{K}\right)\right],
$$

where $\Lambda_{t, t+1}=\beta \frac{C_{t}}{C_{t+1}}$ denotes the real discount factor, and an asset pricing equation for the marginal value of a job to the household,

$$
V_{t}^{N}=\frac{W_{t}}{P_{t}}-\chi N_{t}^{\varphi} C_{t}-\frac{x_{t}}{1-x_{t}} V_{t}^{N}+\left(1-\delta_{N}\right) E_{t} \Lambda_{t, t+1} V_{t+1}^{N}
$$

where $V_{t}^{N}$ is the Lagrange multiplier associated with the employment law of motion. Equation (7) comes in at the bargaining stage, examined below.

Eq.(6) equalizes the cost of one unit of capital to the discounted value of the expected rental rate plus the continuation value of future undepreciated capital. The value of a job, $V_{t}^{N}$ in eq.(7), is equal to the real wage, net of the opportunity cost of work, $\chi N_{t}^{\varphi} C_{t}$, and the re-employment value for unemployed workers, plus a continuation value. It is worth noting that relative to the DMP model, where the opportunity cost of work is assumed to be constant, deriving the net value of employment from a standard problem of the household implies that this opportunity cost equals the marginal rate of substitution between consumption and leisure. As we show later in the text, this feature of the model is key in generating endogenous real wage rigidity in the presence of hiring frictions.

\subsection{Firms}

\subsubsection{Intermediate and final good firms}

We assume two types of firms: intermediate good producers and final good producers. Both firms have a unit measure. Intermediate firms, indexed by $i$, produce a differentiated good $Y_{t, i}$ using labor and capital as inputs of production. At the beginning of each period, capital is rented from the households at the competitive rental rate $R_{t}^{K}$, and workers are hired in a frictional market. Next, wages are negotiated. We elaborate on hiring and wage setting below. The constant returns to scale production function is $f\left(A_{t}, N_{t, i}, \breve{K}_{t, i}\right)=A_{t} N_{t, i}^{\alpha} \breve{K}_{t, i}^{1-\alpha}$, where $\breve{K}_{t, i}$ denotes the demand for capital at time $t$, and $A_{t}$ is a standard TFP shock that follows the stochastic process: $\ln A_{t}=\rho_{a} \ln A_{t-1}+e_{t}^{a}$, with $e_{t}^{a} \sim N\left(0, \sigma_{a}\right)$.

When setting the price $P_{t, i}$ under monopolistic competition, the representative intermediate firm faces price frictions à la Rotemberg (1982). This means that firms face quadratic price adjustment costs, given by $\frac{\zeta}{2}\left(\frac{P_{t+s, i}}{P_{t+s-1, i}}-1\right)^{2} Y_{t+s}$, where $\zeta$ is a parameter that governs the degree of price rigidity, and $Y_{t}$ denotes aggregate output. The latter is produced by final good firms 
as a bundle of all the intermediate goods in the economy, and is sold to the households in perfect competition. Specifically, this aggregate output good, which is used for consumption and investment, is a Dixit-Stiglitz aggregator of all the differentiated goods produced in the economy:

$$
Y_{t}=\left(\int_{0}^{1} Y_{t, i}(\epsilon-1) / \epsilon d i\right)^{\epsilon /(\epsilon-1)},
$$

where $\epsilon$ denotes the elasticity of substitution across goods. The price index associated with this composite output good is:

$$
P_{t}=\left(\int_{0}^{1} P_{t, i}^{1-\epsilon} d i\right)^{1 /(1-\epsilon)},
$$

and the demand for the intermediate $\operatorname{good} i$ is:

$$
Y_{t, i}=\left(\frac{P_{t, i}}{P_{t}}\right)^{-\epsilon} Y_{t}
$$

\subsubsection{Hiring Frictions}

As noted, at the beginning of each period, intermediate good firms rent capital services from the households and hire new workers subject to the law of motion:

$$
N_{t, i}=\left(1-\delta_{N}\right) N_{t-1, i}+H_{t, i}, \quad 0<\delta_{N}<1,
$$

which implies that new hires are immediately productive.

It is assumed that hiring is a costly activity. In the simple model presented here we will restrict attention to internal costs of hiring only, excluding external costs. We will therefore interpret hiring costs as training costs and other costs that are related to the hiring rate. As discussed in Section 2.2 above, these costs are estimated to be much higher than external costs. In Section 6 we will introduce both costs, and investigate their separate role.

The modelling of these costs follows previous work by Merz and Yashiv (2007), Gertler Sala and Trigari (2008), Christiano, Trabandt, and Walentin (2011), Sala, Soderstrom, and Trigari (2013), and Furlanetto and Groshenny (2016). All these studies assume that these costs are a function of the hiring rate, which is the ratio of new gross hires to the workforce, $\frac{H_{t, i}}{N_{t, i}}$. The cited studies assume that the friction cost function is constant returns to scale and quadratic in the hiring rate, in line with estimates by Yashiv $(2016,2017)$. Thus, we assume that internal costs are governed by the friction cost function

$$
g\left(A_{t}, H_{t, i}, N_{t, i}, \breve{K}_{t, i}\right)=\frac{e}{2}\left(\frac{H_{t, i}}{N_{t, i}}\right)^{2} f\left(A_{t}, N_{t, i} \breve{K}_{t, i}\right)
$$

where $e$ is a positive parameter governing the degree of hiring frictions.

As discussed in Section 2.2 above, the functional form above is rather standard. Unlike most of the papers in the literature, we assume that hiring costs are not pecuniary, that is, they 
are not purchases of the composite good, which has price $P_{t}$, but a disruption to production or equivalently, forgone output. That is, we assume that the net output of a representative firm $i$ at time $t$ is:

$$
Y_{t, i}=f_{t, i}-g_{t, i}
$$

\subsubsection{Optimal Behavior}

Intermediate firms maximize current and expected discounted profits:

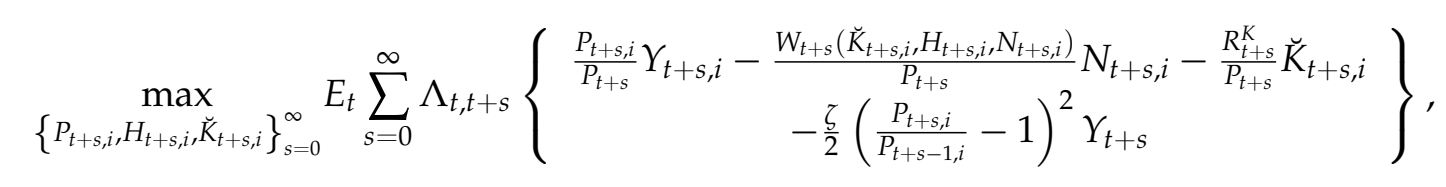

substituting for $Y_{t+s, i}$ using the demand function (10), and subject to the law of motion for labor (11), and the constraint that output must equal demand:

$$
\left(\frac{P_{t, i}}{P_{t}}\right)^{-\epsilon} Y_{t}=f\left(A_{t}, N_{t, i} \breve{K}_{t, i}\right)-g\left(A_{t}, H_{t, i}, N_{t, i}, \breve{K}_{t, i}\right)
$$

which is obtained by combining equations (10) and (13). ${ }^{7}$

The term $\Lambda_{t, t+s}=\beta^{s} \frac{C_{t}}{C_{t+s}}$ in the maximization problem above is the real discount factor of the households, who own the firms.

The first order condition with respect to $P_{t, i}$ reads:

$$
\begin{aligned}
Y_{t, i} & -\zeta\left(\frac{P_{t, i}}{P_{t-1, i}}-1\right) \frac{1}{P_{t-1, i}} P_{t} Y_{t}=\left[P_{t, i}-P_{t} \cdot \Psi_{t}\right] \varepsilon \frac{Y_{t}}{P_{t}}\left(\frac{P_{t, i}}{P_{t}}\right)^{-\varepsilon-1} \\
& -E_{t}\left[\Lambda_{t, t+1} \frac{P_{t}}{P_{t+1}} \zeta\left(\frac{P_{t+1, i}}{P_{t, i}^{2}}\right)\left(\frac{P_{t+1, i}}{P_{t, i}}-1\right) P_{t+1} Y_{t+1,}\right]
\end{aligned}
$$

where $\Psi_{t}$ is the Lagrange multiplier associated with the constraint (15). It represents the shadow value of output, which in equilibrium equals the real marginal cost. This, in turn is the inverse of the price mark-up. It will play an important role in the analysis below.

Since all firms set the same price and therefore produce the same output in equilibrium, the above equation can be rewritten to express a law of motion for inflation:

$$
\pi_{t}\left(1+\pi_{t}\right)=\frac{1-\varepsilon}{\zeta}+\frac{\varepsilon}{\zeta} \Psi_{t}+E_{t} \frac{1}{1+r_{t}}\left(1+\pi_{t+1}\right) \pi_{t+1} \frac{Y_{t+1}}{Y_{t}}
$$

where we have used $E_{t} \Lambda_{t, t+1}=\frac{1}{\left(1+i_{t}\right) /\left(1+\pi_{t+1}\right)}=\frac{1}{1+r_{t}}$, with $i_{t}$ and $r_{t}$ denoting the nominal and real net interest rates, respectively. Equation (17) specifies that inflation depends on the shadow value of output as well as expected future inflation. Solving forward equation (17), it is possible to show that inflation depends on current and expected future real shadow values

\footnotetext{
${ }^{7}$ Note that because of Rotemberg costs of price adjustment, the wage function does not depend on idiosyncratic firm prices. For an analysis of the mechanism produced by the interaction between hiring and price setting under Calvo pricing see Kuester (2010).
} 
of output.

As all firms are symmetric we drop the firm sub-script. The first-order conditions with respect to $H_{t}, N_{t}$ and $\breve{K}_{t}$, are:

$$
\begin{gathered}
Q_{t}^{N}=\Psi_{t}\left(f_{N, t}-g_{N, t}\right)-\frac{W_{t}}{P_{t}}-\frac{W_{N, t}}{P_{t}} N_{t}+\left(1-\delta_{N}\right) E_{t} \Lambda_{t, t+1} Q_{t+1}^{N}, \\
Q_{t}^{N}=\Psi_{t} g_{H, t}+\frac{W_{H, t}}{P_{t}} N_{t}, \\
\frac{R_{t}^{K}}{P_{t}}=\Psi_{t}\left(f_{k, t}-g_{k, t}\right)-\frac{W_{K, t}}{P_{t}} N_{t},
\end{gathered}
$$

where $Q_{t}^{N}$ is the Lagrange multiplier associated with the employment law of motion. One can label $Q_{t}^{N}$ as Tobin's $Q$ for labor or the value of labor. For an extensive discussion of its economic significance, see Yashiv $(2016,2017)$.

Here we notice that the value of a marginal job in equation (18) can be expressed as the sum of current-period profits (the first three terms on the RHS) and a continuation value. The profits equal the marginal revenue product of labor $\Psi_{t}\left(f_{N, t}-g_{N, t}\right)$ less the real wage and the intrafirm bargaining term $\frac{W_{N, t}}{P_{t}} N_{t}$. The latter term appears because the marginal product of labor decreases with the size of the firm, hence the marginal worker decreases the marginal product of labor and the wage bargained by all the infra-marginal workers. In turn, this leads to over-hiring in steady-state. In equation (19), the value of jobs is equated to the real marginal cost of hiring. The real marginal cost of hiring in turn is given by the sum of a frictional component $\Psi_{t} g_{H, t}$, and the intra-firm bargaining component $\frac{W_{H, t}}{P_{t}} N_{t}$. Note that because hiring entails an opportunity cost of production, the marginal hiring cost depends on the shadow value of output $\Psi_{t}$.

The rental cost of capital on the LHS of equation (20) equals the marginal revenue product of capital $\Psi_{t}\left(f_{K, t}-g_{K, t}\right)$ plus an intrafirm bargaining term. The reason for the appearance of the latter is the following: a higher capital stock makes workers more productive, thereby increasing the expected marginal product of labor and the wage bargained by all infra-marginal workers. This term reflects a typical hold-up problem: because workers appropriate part of the rents generated by employment, the capital effect on wages decreases the value of capital, leading to under-investment.

In order to understand the forces driving the shadow value of output, it is worth solving the F.O.C. for employment in equation (18) for $\Psi_{t}$, after replacing for $Q_{t}^{N}$ using (19):

$$
\begin{aligned}
\Psi_{t} & =\frac{\frac{W_{t}}{P_{t}}}{f_{N, t}-g_{N, t}}+\frac{\frac{W_{N, t}}{P_{t}} N_{t}}{f_{N, t}-g_{N, t}} \\
+ & \frac{\left(\Psi_{t} g_{H, t}+\frac{W_{H, t}}{P_{t}} N_{t}\right)-\left(1-\delta_{N}\right) E_{t} \Lambda_{t, t+1}\left(\Psi_{t+1} g_{H, t+1}+\frac{W_{H, t+1}}{P_{t+1}} N_{t+1}\right)}{f_{N, t}-g_{N, t}} .
\end{aligned}
$$

The above expression equalizes the shadow value of output (on the LHS) with the real 
marginal cost (on the RHS).

The first term on the RHS is the wage component of the real marginal cost, expressed as the ratio of real wages to the net marginal product of labor. Because the production function is Cobb-Douglas, in the case of a NK model with $g_{N, t}=0$, the wage component is proportional to the familiar labor share of income $W_{t} N_{t} / P_{t} Y_{t}$.

The second term relates to intrafirm bargaining: the cost of expanding output by raising employment at the margin, decreases with the negative effect of firm size on the negotiated wage bill.

The third term shows that with frictions in the labor market, the real marginal cost also depends on expected changes in the real marginal costs of hiring, a point already made by Krause, Lopez-Salido and Lubik (2008). So, for instance, an expected increase in marginal hiring costs $E_{t} \Lambda_{t, t+1} \Psi_{t+1} g_{H, t+1}$ translates into a lower current real marginal cost, reflecting the savings of future recruitment costs that can be achieved by recruiting in the current period.

\subsection{Wage Bargaining}

We posit that hiring costs are sunk for the purpose of wage bargaining. This follows the standard approach in the literature; see Gertler, Sala, and Trigari (2008), Pissarides (2009), Christiano, Trabandt and Walentin (2011), Sala, Soderstrom and Trigari (2012), Furlanetto and Groeshny (2016), and Christiano, Eichenbaum, and Trabandt (2016).

When maximizing its market value, defined as the present discounted value of future cash flows, the representative producer anticipates the impact of its hiring and capital rental policy on the bargained wage. This is so because with frictions in the labor market, wages are not set competitively and there is bilateral monopoly power in bargaining. Hence the effect of production inputs on the marginal product of labor must be factored in the bargaining (see Cahuc, Marque and Wasmer (2008)). ${ }^{8}$

Wages are therefore assumed to maximize a geometric average of the household's and the firm's surplus weighted by the parameter $\gamma$, which denotes the bargaining power of the households:

$$
W_{t}=\arg \max \left\{\left(V_{t}^{N}\right)^{\gamma}\left(Q_{t}^{N}\right)^{1-\gamma}\right\} .
$$

The first order condition to this problem leads to the sharing rule:

$$
(1-\gamma) V_{t}^{N}=\gamma Q_{t}^{N}
$$

Substituting (7) and (18) into the above equation and using the sharing rule (23) to eliminate the terms in $Q_{t+1}^{N}$ and $V_{t+1}^{N}$ one gets the following expression for the real wage:

$$
\frac{W_{t}}{P_{t}}=\gamma \Psi_{t}\left(f_{N, t}-g_{N, t}\right)-\gamma \frac{W_{N, t}}{P_{t}} N_{t}+(1-\gamma)\left[\chi C_{t} N_{t}^{\varphi}+\frac{x_{t}}{1-x_{t}} \frac{\gamma}{1-\gamma} Q_{t}^{N}\right] .
$$

\footnotetext{
${ }^{8}$ In Section (6) we relax the assumption of intrafirm bargaining as we introduce real wage rigidity. By doing so, we provide robustness to this alternative wage setting. For theoretical foundations on wage bargaining between a firm and multiple employees see Brugemann, Gautier, and Menzio (2017); this has been implemented to the current context by Cahuc, Marque and Wasmer (2008).
} 
Using our Cobb-Douglas production function and the frictions cost function in (12), the solution to the differential equation in (24) reads as follows:

$$
\frac{W_{t}}{P_{t}}=\gamma \Psi_{t} A_{t} K_{t-1}^{1-\alpha}\left\{\frac{\alpha N_{t}^{\alpha-1}}{1-\gamma(1-\alpha)}+\frac{e\left(1-\frac{\alpha}{2}\right) H_{t}^{2} N_{t}^{\alpha-3}}{1-\gamma+\gamma(\alpha-2)}\right\}+(1-\gamma)\left[\chi C_{t} N_{t}^{\varphi}+\frac{x_{t}}{1-x_{t}} \frac{\gamma}{1-\gamma} Q_{t}^{N}\right]
$$

See Appendix A for the details of the full derivation.

\subsection{The Monetary and Fiscal Authorities and Market Clearing}

We assume that the government runs a balanced budget:

$$
T_{t}=B_{t}-\frac{B_{t+1}}{R_{t}}
$$

and the monetary authority sets the nominal interest rate following the Taylor rule:

$$
\frac{R_{t}}{R^{*}}=\left(\frac{R_{t-1}}{R^{*}}\right)^{\rho_{r}}\left[\left(\frac{1+\pi_{t}}{1+\pi^{*}}\right)^{r_{\pi}}\left(\frac{Y_{t}}{Y^{*}}\right)^{r_{y}}\right]^{1-\rho_{r}} \xi_{t}
$$

where $\pi_{t}$ measures the rate of inflation of the aggregate good, i.e., $\pi_{t}=\frac{P_{t}-P_{t-1}}{P_{t}}$, and an asterisk superscript denotes the steady-state values of the associated variables. When linearizing the model around the stationary equilibrium we will assume that $\pi^{*}=0$. The parameter $\rho_{r}$ represents interest rate smoothing, and $r_{y}$ and $r_{\pi}$ govern the response of the monetary authority to deviations of output and inflation from their steady-state values. The term $\xi_{t}$ captures a monetary policy shock, which is assumed to follow the autoregressive process $\ln \xi_{t}=\rho_{\xi} \ln \xi_{t-1}+e_{t}^{\xi}$, with $e_{t}^{\xi} \sim N\left(0, \sigma_{\xi}\right)$.

Consolidating the households and the government budget constraints, and substituting for the firm profits yields the market clearing condition:

$$
\left(f_{t}-g_{t}\right)\left[1-\frac{\zeta}{2} \pi_{t}^{2}\right]=C_{t}+I_{t}
$$

Finally, clearing in the market for capital implies that the capital demanded by the firms equals the capital supplied by the households, $\breve{K}_{t}=K_{t-1}$.

\section{Empirical Implementation}

In order to study the mechanisms showing the role of hiring frictions, we empirically implement the model. This section presents the calibration and the resulting impulse responses. The analysis of the mechanisms is then undertaken in the next section.

We start by calibrating the model with price frictions and hiring frictions, which provides a benchmark for the analysis to follow. We then compare how the impulse responses of real variables such as the hiring rate, the investment rate, real wages and net output change as 
we vary the degree of price frictions and hiring frictions. In what follows we look at both technology and monetary policy shocks. We linearize the model around the non-stochastic steady state and solve for the policy functions, which express the control variables as a function of the states and the shocks. We then shock the stationary equilibrium of the model with a technological or a monetary innovation, and iterate on the policy functions and on the laws of motion for the state variables to trace the expected behavior of the endogenous variables, i.e., we produce impulse responses.

\subsection{Calibration}

Parameter values are set so that the steady-state equilibrium of our model matches key averages of the 1976Q1-2014Q4 U.S. economy, assuming that one period of time equals one quarter. We start by discussing the parameter values that affect the stationary equilibrium.

\section{Table 1}

The discount factor $\beta$ equals 0.99 implying a quarterly interest rate of $1 \%$. The quarterly job separation rate $\delta_{N}$, measuring separations from employment into either unemployment or inactivity, is set at 0.126 , and the capital depreciation rate $\delta_{K}$ is set at 0.024 . These parameters are selected to match the hiring to employment ratio, and the investment to capital ratio measured in the US economy over the period 1976Q1-2014Q4 (see Appendix B in Yashiv (2016) for details on the computations of these series).

The inverse Frisch elasticity $\varphi$ is set equal to 4 , in line with the synthesis of micro evidence reported by Chetty et al. (2013), pointing to Frisch elasticities around 0.25 on the extensive margin. The elasticity of substitution in demand $\epsilon$ is set to the conventional value of 11 , implying a steady-state markup of 10\%, consistent with estimates presented in Burnside (1996) and Basu and Fernald (1997). Finally, the scale parameter $\chi$ in the utility function is normalized to equal 1 and the elasticity of output to the labor input $\alpha$ is set to 0.66 to match a labor share of income of about two thirds.

This leaves us with two parameters to calibrate: the bargaining power $\gamma$, and the scale parameter in the friction costs function $e$. These two parameters are calibrated to match: i) a ratio of marginal hiring friction costs to the average product of labor, $g_{H} /[(f-g) / N]$, equal to 0.20 reflecting estimates by Yashiv (2016); ii) An unemployment rate of $10.6 \%$. This value is the average of the time series for expanded unemployment rates produced by the BLS designed to account also for workers who are marginally attached to the labor force (U-6), consistently with our measure of the separation rate. ${ }^{9}$ We also note that the calibration implies a ratio of the opportunity cost of work to the marginal revenue product of labor of 0.77 , which turns out to be close to the value of 0.745 advocated by Costain and Reiter (2008).

In sub-section 2.2 above we have discussed our modelling of the frictions cost function in the context of the literature. It is worthwhile to comment on the magnitude of hiring frictions as calibrated here. Following our discussions above, note that hiring costs are to be interpreted

\footnotetext{
${ }^{9}$ BLS series can be downloaded at: http:// data.bls.gov/pdq/SurveyOutputServlet
} 
in terms of training costs as well as all other sources of forgone output associated with hiring. In our calibration we follow the structural estimates in Yashiv (2016) for U.S. data and adopt a conservative magnitude relative to the literature: the calibration target for marginal hiring friction costs in point (i) above implies a ratio of marginal hiring costs over steady state wages $\frac{\Psi \cdot g_{H t}}{W / P}$ around $27 \%$, i.e., less than one month of wages. ${ }^{10}$ We focus on marginal hiring friction costs, while the empirical literature typically reports numbers for average hiring costs. The latter, computed as $g_{t} / H_{t}$, are close to two weeks of wages in our calibration. This calibration of hiring costs is conservative in the sense that average and marginal frictions costs lie at the low part of the spectrum of estimates reported in the literature. The widely-cited study of Silva and Toledo (2009) reports that average training costs are about $55 \%$ of quarterly wages. ${ }^{11}$ In the Blatter et al (2016) survey of the literature, hiring costs, in terms of equivalent wage payments, range between 1 week and 17 weeks of wages, across different economies and different studies.

Note that in our model the cost of hiring a marginal worker also includes, on top of the training costs discussed above $\left(g_{H, t}\right)$, the intrafirm bargaining costs $N_{t} W_{H, t} / P_{t}$ (see equation 19). These intrafirm marginal costs of hiring are equal to one month of wage payments.

Turning to the remaining parameters that have no impact on the stationary equilibrium, we set the Taylor rule coefficients governing the response to inflation and output to 1.5 and 0.125, respectively, as in Galí (2011), while the degree of interest rate smoothing captured by the parameter $\rho_{r}$ is set to the conventional value of 0.75 as in Smets and Wouters (2007).

The Rotemberg parameter governing price stickiness is set to 120 , to match a slope of the Phillips curve of about 0.08, as implied by Galís (2011) calibration. ${ }^{12}$ As for the technology shocks, we assume an autocorrelation coefficient $\rho_{a}=0.95$, while monetary policy shocks are assumed to be i.i.d.

\subsection{Impulse Responses}

We show how the impulse responses obtained on the impact of technology and monetary policy shocks change across different parameterizations of hiring and price frictions. This is convenient to illustrate the interaction produced by hiring frictions and price frictions, for which we provide intuition in the next Section. Specifically, for each shock we plot the response of four variables: hiring rates, investment rates, real wages, and output. Using 3D graphs, for each variable we look at how the response on impact changes as we change the parameters governing price frictions, $\zeta$, and hiring frictions, $e$. All other parameter values remain fixed at

\footnotetext{
${ }^{10}$ The hiring rate $H_{t} / N_{t}$ in the data lies in the interval $[0.110,0.152]$ in the period 1976Q1-2014Q4. Hence the implied ratio of $\frac{\Psi \cdot g_{H t}}{W / P}$, using our calibration values, ranges between $24 \%$ and $33 \%$ of quarterly wages. This represents relatively little variation and an upper bound that is well below the training costs found in the literature. This exercise also shows that the convexity assumed in the hiring cost function (12) is mild.

${ }^{11}$ This figure is nearly ten times as large as that of vacancy posting costs. The papers of Krause, Lopez-Salido and Lubik (2008) and Galí (2011) assume that average vacancy costs equal to around 5\% of quarterly wages, following empirical evidence by Silva and Toledo (2009) on vacancy advertisement costs.

${ }^{12}$ Our value for $\zeta$ is obtained by matching the same slope of the linearized Phillips Curve as in Gali: $\frac{\varepsilon-1}{\zeta}=$ $\frac{\left(1-\theta_{p}\right)\left(1-\beta \theta_{p}\right)}{\theta_{p}}$, where $\theta_{p}$ is the Calvo parameter. Notice that for given values of $\varepsilon$ and $\beta$, this equation implies a unique mapping between $\theta_{p}$ and $\zeta$. While Gali (2011) assumes Calvo pricing frictions, with $\theta_{p}=0.75$, we adopt Rotemberg pricing frictions, which implies that in our specification prices are effectively reset every quarter.
} 
the calibrated values reported in Table 1. The impulse responses obtained over the full horizon will be presented in Section 6 for a richer version of the model. The full-horizon impulse responses for the simple model considered here are relegated to Appendix B.

Impulse responses to technology shocks and to monetary policy shocks upon impact are reported in Figures 1 and 2, respectively.

\section{Figures 1 and 2}

The area colored in blue (red) denotes the pairs of $(\zeta, e)$ for which the impact response is positive (negative). One aspect of the analysis to note is that the figures feature reasonable ranges of parameter values. For instance, the price stickiness parameter $\zeta \in(0,150]$ covers a range of values governing price rigidity that range from full flexibility to considerable stickiness, whereby the upper bound value for $\zeta$, in Calvo space would correspond to an average frequency of price negotiations of four-and-a-half quarters. The hiring frictions parameter $e \in(0,5]$ ranges from the frictionless benchmark to a value of average hiring costs equal to approximately one and a half months of wages, which is the average training cost reported in Silva and Toledo (2009). The reader can choose a region in the 3D space conforming to his/her own priors to gauge the results.

For expositional convenience, we mark with colored points in the figure four reference points, which correspond to four model variants and are associated with the following different parameterizations: (i) the model with both frictions - the NK model embodying price frictions together with hiring frictions (green point); (ii) the NC model with hiring costs; this is obtained by setting a level of price frictions close to zero, i.e. $\zeta \simeq 0$, while maintaining hiring frictions as in the baseline calibration (blue point); (iii) the standard NK model obtained by maintaining a high degree of price frictions, i.e. $\zeta=120$, but setting hiring costs close to zero, i.e. $e \simeq 0$ (red point); (iv) the NC model with no frictions obtained by setting $\zeta \simeq 0$ and $e \simeq 0$ (black point). ${ }^{13}$

We emphasize that while we indicate four points in this space, corresponding to the models under review, these serve as reference points and the graphs offer a "bigger picture".

\section{Technology Shocks}

We begin by noting that in the case where both price and hiring frictions are shut down, the model delivers the standard NC results whereby a technology shock increases hiring and employment, investment, real wages and output (see the black points in Figure 1). Adding hiring frictions to this frictionless benchmark, i.e., moving from the black to the blue points, results in relatively small changes, which reflect the moderate size of hiring frictions. The responses

\footnotetext{
${ }^{13}$ We set the parameter $e$ close to zero and not exactly equal to zero for ease of exposition. Notice that in the limit of $e \rightarrow 0$, the solution does not converge to the frictionless equilibrium because the wage in eq. (24) does not converge exactly to the marginal product of labor due to the intrafirm bargaining term $W_{t}^{N}$. Moreover, for $e=0$ there is no unemployment, and in the frictionless labor market equilibrium the restriction $n_{t}+u_{t}=1$ must be lifted to analyze business cycle dynamics. So the model has a discontinuity at $e=0$. Labelling the model with $e \simeq 0$ as "New Classical" is therefore a slight abuse of terminology. Yet, solving the model with a totally frictionless labor market for different values of $\zeta$, would show the same qualitative pattern reported in Figures 3 and 4 below. Hence we abstract from this minor complication for illustrative purposes.
} 
appear somewhat smoothed by the presence of hiring frictions, recovering the conclusions of Rogerson and Shimer (2011) that hiring frictions operate as an adjustment cost, thereby exacerbating the difficulties of the standard NC model to account for the cyclical behavior of the labor market.

Adding price frictions to the NC model, i.e. moving from the black to the red point, recovers the standard NK results that hiring and employment fall on the impact of technology shock, reversing the standard NC results. This is of course well known, but serves to place the results in context.

Adding hiring frictions to the NK model, that is, moving from the red point to the green point generates very substantial differences. Note that there are only moderate to small differences relative to the black points, i.e., the frictionless NC model. The idea, then, is that the model with all the frictions together can yield outcomes that are close to the frictionless benchmark, even with the small values of hiring frictions imposed in the calibration. This result is very different from the one obtained by Galí (2011), that the propagation of shocks is virtually unaffected by labor market frictions. In Section 6.3.2 we show that Galís (2011) results can be recovered as the special case where hiring costs are only related to vacancy posting.

Interestingly, we also note that adding hiring frictions to the NK benchmark makes real wages respond by less, hence generating endogenous real wage rigidity (compare the red and green point in the second panel). Finally, looking at the first panel of Figure 1, we point out that for values of both price and hiring frictions that are relatively high - but within plausible empirical estimates - the hiring rate responds positively to technology shocks, and the response increases with hiring frictions. In this region of the parameter space the model generates amplification of employment responses relative to the NC benchmark. That is, with regards to technology shocks, the NK model can generate an increase in employment, just as in the NC model, but can potentially overcome the issues related to lack of amplification. These counterintuitive results, whereby hiring frictions can magnify the response of employment to shocks, will be the focus of the next Section.

\section{Monetary Policy Shocks}

Turning to monetary policy shocks in Figure 2, the impulse responses show that in the absence of price frictions, monetary policy is neutral, independently of labor market frictions (compare the black and blue points). In the NK benchmark instead (red point), the monetary policy shock has real effects, which lead to an increase in employment, investment, output and real wages. Most importantly, real variables respond very differently in the NK model without (red point) and with (green point) hiring frictions. Introducing hiring frictions virtually eliminates all real effects of monetary policy shocks, so that for all real variables except wages, the response of the NK model with hiring frictions is indistinguishable from the response of the NC benchmark. Increasing frictions even further can generate contractionary effects of policy on the impact of expansionary monetary shocks.

We also notice that the response of real wages is smoothed when hiring frictions are introduced into the baseline NK model. Hence, in analogy with the case of technology shocks, 
hiring frictions generate endogenous real wage rigidity.

We conclude that hiring frictions matter substantially in the transmission of both technology and monetary policy shocks. Specifically, these frictions offset and potentially reverse the impact of price frictions on the propagation of shocks. In what follows we elucidate the mechanism that generates these results and explain what brings about the differences.

\section{Exploring the Mechanism: The Role of Hiring Frictions}

We aim to study the mechanisms producing the afore-going results: namely, (i) "NC-type outcomes" even with price frictions; (ii) amplification of real responses, in particular of labor market outcomes, as hiring frictions rise; (iii) endogenous wage rigidity; (iv) much smaller real effects for monetary policy.

To understand the transmission of both shocks in the presence of hiring frictions, it is important to understand what drives the hiring decision. For this purpose it is useful to write the optimality condition for gross hiring by merging the F.O.C. (18) and (19):

$$
\Psi_{t}\left(f_{N, t}-g_{N, t}\right)-\frac{W_{t}}{P_{t}}-\frac{W_{N, t}}{P_{t}} N_{t}+\left(1-\delta_{N}\right) E_{t} \Lambda_{t, t+1} Q_{t+1}^{N}=\Psi_{t} g_{H, t}+\frac{W_{H, t}}{P_{t}} N_{t} .
$$

The LHS is the expected present value of a marginal job, $Q_{t}^{N}$. This value is made up of current profits from the marginal hire $\left(\Psi_{t}\left(f_{N, t}-g_{N, t}\right)-\frac{W_{t}}{P_{t}}-\frac{W_{N, t}}{P_{t}} N_{t}\right)$ and the expected future discounted profits $\left(E_{t} \Lambda_{t, t+1} Q_{t+1}^{N}\right)$, conditional on no-separation $\left(1-\delta_{N}\right)$. The RHS is the real marginal cost of hiring, consisting of the marginal gross hiring costs $\left(\Psi_{t} g_{H, t}\right)$ and the cost effects of the marginal hire on the wage bill $\left(\frac{W_{H, t}}{P_{t}} N_{t}\right)$. We shall use this representation in what follows.

\subsection{The Effects of Technology Shocks}

We depict the mechanism, showing how the different frictions affect the propagation of a technology shock. Note that a positive technology shock decreases the shadow value of output $\Psi_{t}$. This fall is induced by the increase in the net marginal product of labor on the RHS of equation (21). Intuitively, price rigidities imply that after an expansionary technology shock demand cannot rise to meet the increase in supply. This excess supply induces a fall in the shadow value of production. Only in the special case where prices are fully flexible, the shadow value of output does not move. ${ }^{14}$ The higher are price frictions, the stronger is the fall in $\Psi_{t}$. The role of price frictions is thus expressed strongly through changes in the shadow value of output.

The mechanism is somewhat involved so we proceed in steps.

Two propagation channels. With frictions in the labor market, the hiring decision is a dynamic problem that depends on the expectation of the entire sequence of the future states of technology. To understand the propagation of technology shocks in this framework, it is useful to re-arrange the LHS of equation (29) substituting for the wage function (24) and its derivative

\footnotetext{
${ }^{14}$ Eq.(16) implies that the shadow value of output (real marginal cost) is constant at the value of $\frac{\varepsilon-1}{\varepsilon}$ in the case of $\zeta=0$.
} 
$\frac{W_{N, t}}{P_{t}}$, and iterating forward on $Q_{t}^{N}:{ }^{15}$

$$
\begin{gathered}
\sum_{s=0}^{\infty}\left(1-\delta_{N}\right)^{s} E_{t} \Lambda_{t, t+s}(1-\gamma)\left[\mathbf{\Psi}_{\mathbf{t}+\mathbf{s}}\left(\mathbf{f}_{\mathbf{N}, \mathbf{t}+\mathbf{s}}-\mathbf{g}_{\mathbf{N}, \mathbf{t}+\mathbf{s}}+\mathbf{D}_{\mathbf{t}+\mathbf{s}}^{1}\right)-D_{t+s}^{2}\right]= \\
\frac{W_{H, t}\left(\mathbf{\Psi}_{t}\right)}{P_{t}} N_{t}+\mathbf{\Psi}_{t} g_{H, t} .
\end{gathered}
$$

The term $D_{t}^{1}$, which is positive in the calibration, reflects the fall in the wage bill engendered by the marginal hire. ${ }^{16}$ Hence, the term $f_{\mathbf{N}, \mathbf{t}+\mathbf{s}}-g_{\mathbf{N}, \mathbf{t}+\mathbf{s}}+D_{\mathbf{t}+\mathbf{s}}^{1}$ represents the net marginal product of labor, adjusted for intrafirm bargaining. We let $D_{t}^{2}=\chi C_{t} N_{t}^{\varphi}+\frac{x_{t}}{1-x_{t}} \frac{\gamma}{1-\gamma} Q_{t}^{N}$ denote the outside option of the worker.

The propagation of technology shocks operates via two main channels. The first one is the standard NC mechanism as in Shimer (2005): an increase in the current and future expected states of technology raises the net marginal product of labor on the LHS of eq.(30). In turn, this increases the expected profits from the marginal hire, leading to more hiring and employment. The second channel operates only in the presence of price rigidities. Indeed, the inability of prices to fully adjust to clear the markets leads to a fall in the current and future expected values of $\Psi_{t}$. The shadow value of output appears both on the LHS and on the RHS of the job creation condition, eq.(30). Hence, a fall in the shadow value of output decreases both the profits and the costs of a marginal hire, with ambiguous effects on hiring. To resolve this ambiguity, it is instructive to inspect how the fall in the shadow value of output affects the marginal hiring cost.

The relation between the shadow value of output and the marginal hiring cost. We spell out the two terms on the RHS of (30), by replacing for the friction cost $g_{H, t}$ using the functional form in (12):

$$
\Psi_{t} g_{H, t}=\Psi_{\mathbf{t}} \mathbf{e} A_{t}\left(K_{t-1} / N_{t}\right)^{1-\alpha} \frac{H_{t}}{N_{t}}
$$

and differentiating the wage function (25) with respect to hiring:

$$
\frac{W_{H, t}}{P_{t}} N_{t}=\Psi_{t} \mathbf{e} \frac{\gamma A_{t}\left(K_{t-1} / N_{t}\right)^{1-\alpha}(2-\alpha)}{1-\gamma+\gamma(\alpha-2)} \frac{H_{t}}{N_{t}} .
$$

We note that $\Psi_{t} g_{H, t}$ is always positive, and $\frac{W_{H, t}}{P_{t}} N_{t}$ is positive in the calibration.

The impact of a change in the shadow value of output $\Psi_{t}$ on marginal hiring costs is there-

\footnotetext{
${ }^{15}$ We denote in bold variables, which role we want to highlight in the analysis.

${ }^{16}$ The term $D_{t}^{1}$ is obtained by deriving the wage function in equation (25), and equals:$$
D_{t}^{1} \equiv \frac{-\frac{W_{N, t}}{P_{t}} N_{t}}{\Psi_{t}}=\gamma A_{t}\left(\frac{K_{t-1}}{N_{t}}\right)^{1-\alpha}\left[\frac{\alpha(1-\alpha)}{1-\gamma(1-\alpha)}+\left(1-\frac{\alpha}{2}\right) \frac{e(3-\alpha)}{1-\gamma(3-\alpha)}\left(\frac{H_{t}}{N_{t}}\right)^{2}\right]
$$ 
fore:

$$
\frac{\partial\left(\frac{W_{H, t}}{P_{t}} N_{t}+\Psi_{t} g_{H, t}\right)}{\partial \Psi_{t}}=\mathbf{e} \frac{H_{t}}{N_{t}} A_{t}\left[\frac{\gamma\left(K_{t-1} / N_{t}\right)^{1-\alpha}(2-\alpha)}{1-\gamma+\gamma(\alpha-2)}+\left(K_{t-1} / N_{t}\right)^{1-\alpha}\right]=\frac{Q_{t}^{N}}{\Psi_{t}}
$$

The first equality in the derivative above reveals that a fall in $\Psi_{t}$ will decrease both components of the marginal cost of hiring for any $e>0$, and the extent of this fall increases with the value of $e$. The second equality shows that this effect is proportional to the value of a job to the firm.

Comparison to the NK case without hiring frictions. Consider the response of hiring in the case where hiring frictions are negligible, i.e. $Q_{t}^{N} \simeq 0$. In terms of the space in Figure 1, we are looking at the red point, which marks the NK model with no hiring costs. In this case, the fall in the sequence of shadow prices $\left\{\Psi_{t+s}\right\}_{s=0}^{\infty}$ will decrease profits on the LHS of (30), but, by equations (33), will not decrease costs on the RHS of the same equation. Hence, the fall in the shadow value of output unambiguously reduces the incentives for job creation. For conventional parameterizations of the Taylor rule, this effect dominates the direct positive effect of productivity, so employment falls. This is the mechanism at work in the standard NK model. Intuitively, output is demand-driven in the presence of sticky prices. Hence, employment must fall to restore market clearing.

Now note the changes that take place when moving away from the red point in Figure 1, the NK model with price frictions only, towards the green point, marking the NK model with moderate hiring frictions, as well as price frictions. As $e$ increases, the marginal cost of hiring becomes more sensitive to a change in the shadow value of output. For values of $e$ that are sufficiently large, the fall in marginal hiring costs will be large enough to turn the response of hiring from negative to positive. This effect derives from interacting price frictions (which exist at both red and green points) and hiring frictions (which rise going from the red point to the green point).

What matters is that the cost of hiring involves forgone output, which implies that hiring entails an opportunity cost of production. This opportunity cost falls as a result of excess capacity. Hence, firms have an incentive to increase hiring and employment, as the existing workforce is used to train new workers.

Key result. At the calibrated equilibrium, for parameterizations of labor market frictions that reflect conservative estimates of hiring costs (green point), the response of hiring on the impact of technology shocks is positive. We notice that by offsetting the mechanism at work in the NK model, the decline of the shadow value of output on the RHS of (30) produces the counter-intuitive result whereby hiring actually increases with hiring frictions. It is worth noting that in the region of the parameter space where $e$ takes high, but still reasonable values, the response of hiring is stronger than in the flexible price (NC) economy. Hence, and in contrast to the conclusions reached by Rogerson and Shimer (2011), hiring frictions matter for the amplification of employment to technology shocks. This novel result arises because of an interaction between price and hiring frictions, which is absent in DMP models.

Context in the literature. Note that while the interaction mechanism proposed here induces 
countercyclical marginal costs of hiring conditional on technology shocks, in DMP models, where technology shocks are the only source of fluctuations, the hiring costs is procyclical.

This is so, as vacancies increase in expansions, leading to congestion externalities and an increase in the time - and thus overall costs - required to fill jobs. Notably, the amplification mechanism generated by the interaction of hiring and price frictions is very different from the one proposed in this literature. As shown in Sargent and Ljungqvist (2017), any mechanism of amplification in DMP does so by shrinking the fundamental surplus of the match. ${ }^{17}$ In contrast, here the amplification mechanism increases proportionally with the value of jobs.

In most NK models with hiring frictions, marginal hiring costs have been modelled as pecuniary costs rather than forgone output (see the discussion in sub-section 2.2 above and the references therein), and therefore they are not affected by changes in the shadow value $\Psi_{t}$. In these cases, the NK transmission channel qualitatively works in the same way as in the version with no hiring costs. In sub-section 6.4 below we place these findings in the context of the empirical literature.

Endogenous wage rigidity. In the NK model with hiring frictions (the green point), the increase in employment implies that wages fall by less than in the NK model with a frictionless labor market; indeed, higher employment sustains the marginal rate of substitution, which increases the outside option of the workers and thereby dampens endogenously the response of real wages. It is also worth noting that for values of $\zeta$ around 60, which map into a Calvo price stickiness of $2-2 \frac{1}{2}$ quarters, ${ }^{18}$ increasing $e$ can turn the response of real wages to technology shocks from negative to positive, that is, it reproduces the qualitative response that we observe in a NC benchmark. ${ }^{19}$

Effects on capital and output. In the presence of price frictions, increasing hiring frictions implies that investment rises by more. As employment increases with higher labor market frictions $e$, the marginal productivity of capital rises. Finally, output rises substantially as productivity and employment rise.

In summary, as Figure 1 shows, adding conservative estimates of hiring frictions to price frictions brings the NK model closer to the results of the NC model with hiring costs, i.e., offsets to a significant extent the effects of price frictions. Raising frictions even further generates amplification of hiring and employment responses, relative to the flexible price counterpart.

\subsection{The Effects of Monetary Policy Shocks}

In the presence of price rigidities, an expansionary monetary policy shock generates excess output demand, which increases the shadow value of production $\Psi_{t}$. Hence, the rise in $\Psi_{t}$ is

\footnotetext{
${ }^{17}$ This is the case also in Pissarides (2009), who generates amplification by means of a fixed matching cost (see Ljungqvist and Sargent (2017), p.17), and in Christiano, Eichenbaum and Trabandt (2016), who generate amplification by means of a high parameterization of both unemployment benefits and the firm's cost in delaying bargaining using an alternating-offer bargaining protocol (see Ljungqvist and Sargent (2017), p.41).

${ }^{18}$ See footnote 12.

${ }^{19}$ We note that in Figure 1 the real wage response is noticeably further away from the NC+L friction point, unlike the other cases. This happens because the real wage depends on the marginal revenue product, which in turn depends on the shadow price $\Psi_{t}$. Because $\Psi_{t}$ falls only with price frictions, the real wage response will be lower than in the NC case with hiring costs.
} 
proportional to the degree of price frictions $\zeta$. Only in the special case where prices are fully flexible, shadow prices do not respond. Again we proceed in steps.

Two contradictory forces. The key equation to be used here is (30), which we reproduce below for convenience, denoting again key variables with bolded letters:

$$
\begin{gathered}
\sum_{s=0}^{\infty}\left(1-\delta_{N}\right)^{s} E_{t} \Lambda_{t, t+s}(1-\gamma)\left[\mathbf{\Psi}_{t+s}\left(f_{N, t+s}-g_{N, t+s}+D_{t+s}^{1}\right)-D^{2}{ }_{t+s}\right]= \\
\frac{W_{H, t}\left(\mathbf{\Psi}_{t}\right)}{P_{t}} N_{t}+\mathbf{\Psi}_{t} g_{H, t} .
\end{gathered}
$$

An expansionary monetary policy shock produces an increase in the sequence of shadow prices $\left\{\Psi_{t+s}\right\}_{s=0}^{\infty}$. In analogy with the previous discussion of technology shocks, this will increase marginal profits on the LHS of equation (34), which, everything else equal, implies that employment increases; concurrently, it will also increase marginal hiring costs on the RHS of the same equation, which, everything else equal, implies that hiring decreases. Importantly, as with equation (33), the effect of an increase in $\Psi_{t}$ on the two components of marginal hiring costs increases with $e$. The main difference, relative to the case of technology shocks, is that monetary policy shocks affect hiring only through their impact on shadow prices, with no direct effect on productivity.

Comparison to the NK case without hiring frictions. Consider the case where $e \simeq 0$ (the red points in Figure 2 ). Hiring will increase, since the rise in the current and future shadow values of output increases profits, leaving marginal hiring costs unaffected. This is the mechanism at work in the standard NK model. Intuitively, output is demand-driven in the presence of sticky prices. Hence, employment must increase to restore market clearing.

Moving from the red point to the green point, as $e$ rises and the value of a job $Q^{N}$ increases, marginal hiring costs become more sensitive to the shadow price $\Psi_{t}$ (eq.(33)). As the shadow value of output increases, hiring costs will increase too, offsetting the conventional New-Keynesian propagation. Intuitively, excess demand entails an increase in the marginal cost of hiring, which is an opportunity cost of production. In equilibrium, hiring may rise or fall, depending on how strong is the increase in the cost of hiring.

Key results. Our calibration implies that a monetary stimulus is effectively neutral (see green points in Figure 2). For values of hiring frictions that are higher than assumed in our calibration, but still reasonable, the impulse response to monetary policy shocks are contractionary and thus countercyclical, in line with empirical evidence by Nekarda and Ramey (2013), and in contrast to the predictions of the textbook NK model.

Effects on real wages, capital, and output. Because employment is virtually unaffected by a monetary policy shock, the marginal rate of substitution does not rise, unlike in the NK model. Hence, the outside option of the workers does not respond and the response of real wages is endogenously dampened. Because employment does not respond, the productivity of capital remains unchanged, hence investment does not respond. Output also remains unchanged and money is virtually neutral. 
The role of hiring frictions. The simple model presented here highlights the importance of hiring frictions in the transmission of monetary policy shocks. The precise threshold of $e$ that delivers no response of real variables on the impact of the shock will depend both on the parameterizations and on the modelling assumptions. Quite clearly, the simple model we use (outlined in Section 3 above) abstracts from many assumptions that are prevalent in DSGE modelling, and which we include in next Section. But Figure 2 reveals a main theme that remains valid even in larger scale versions of the model presented here: on the one hand, this figure shows that there exists a range of reasonable joint parameterizations for $e$ and $\zeta$, such that the model produces real effects of money. On the other hand, Figure 2 shows that there also exists a wide range of alternative reasonable parameterizations under which monetary policy has smaller real effects, or even contractionary ones. In sub-section 6.4 below we place these findings in the context of the literature.

Here we do not take a stance on whether monetary policy has real effects or not, and in what direction. What we take away from this analysis is that hiring frictions matter for the transmission of monetary policy shocks, and a structural assessment of the transmission of such shocks cannot abstract from a careful quantitative evaluation of hiring frictions.

Note, too, that given the New Keynesian Phillips Curve in equation (17), hiring frictions could also matter for inflation via their effects on current and expected future real marginal costs. ${ }^{20}$ Hence, one would need to re-examine the role of hiring frictions in DSGE models used in central banks. Possibly, the formulation of monetary policy itself could be affected. Thus, the analysis may inform policymakers of variables, such as those related to hiring frictions, that need to be taken into account when setting monetary policy strategies. ${ }^{21}$

\subsection{The Main Lessons}

Using a relatively simple model of the business cycle, we show the effects of shocks on key variables. We relate to empirically-plausible configurations of price and hiring frictions. We explain the mechanisms of moving in this space. It turns out that everywhere, the interaction of the two frictions matters.

In the presence of price rigidities, expansionary technology shocks generate excess supply, whereas expansionary monetary policy shocks induce excess demand. As a result, the shadow value of output falls conditional on a technology shock, and increases conditional on a monetary policy shock. If hiring entails an opportunity cost of production, the marginal cost of hiring will be countercyclical conditional on a technology shock and procyclical conditional on a monetary policy shock.

The main lessons are as follows:

(i) Some well-known, standard models are very special cases.

(ii) The confluence of frictions is important. The cyclicality of the marginal cost of hiring operates so as to offset and possibly reverse the standard New Keynesian propagation. This

\footnotetext{
${ }^{20}$ Sbordone (2005) has empirically confirmed the importance of forward-looking terms in accounting for inflation dynamics.

${ }^{21}$ For example, in inflation-targeting regimes; see the discussion in Giannoni and Woodford (2005).
} 
effect rises with the job value.

(iii) The countercyclicality of hiring costs conditional on technology shocks may induce amplification if job values are high enough.

(iv) The procyclicality of hiring costs conditional on monetary policy shocks dampens, and possibly reverses the conventional transmission of such shocks.

(v) In the DMP model external conditions are key; in our model internal conditions are key. This assumption suppresses the pro-cyclicality of marginal hiring costs that characterizes DMP models.

We now turn to an extended model; the afore-cited lessons from this section survive.

\section{The Medium Scale Model}

\subsection{The Model}

The model laid-out in Section 3 is relatively simple and abstracts from various features that are prevalent in medium-scale DSGE models. In this sub-section we augment the simple model with a matching function, external hiring costs, investment adjustment costs, habits in consumption, exogenous wage rigidity, trend inflation and indexation to past inflation. We do not aim to produce a fully-fledged DSGE model that should be considered as our best characterization of the actual US economy; rather, we want to show that the effects generated by internal hiring frictions remain important even in a richer model. We relegate the full description of the model to Appendix C.

In what follows we summarize the main additions to the model of Section (3). We now assume that in the labor market, unemployed workers and vacancies come together through the constant returns to scale matching function

$$
H_{t}=\frac{U_{0, t} V_{t}}{\left(U_{0, t}^{l}+V_{t}^{l}\right)^{\frac{1}{T}}},
$$

where $H_{t}$ denotes the number of matches - or hires $-V_{t}$ aggregate vacancies, $U_{0, t}$ the aggregate measure of workers who are unemployed at the beginning of each period $t$, and $l$ is a parameter. This matching function was used by Den Haan, Ramey and Watson (2000) and ensures that the matching rates for both workers and firms are bounded above by one. We denote the job finding rate by $x_{t}=\frac{H_{t}}{U_{0, t}}$ and the vacancy filling rate by $q_{t}=\frac{H_{t}}{V_{t}}$.

The law of motion for physical capital follows the process:

$$
K_{t}=\left(1-\delta_{K}\right) K_{t-1}+\left[1-S\left(\frac{I_{t}}{I_{t-1}}\right)\right] I_{t}
$$

where $S$ is an investment adjustment cost function, and it is assumed that $S(1)=S^{\prime}(1)=0$, and $S^{\prime \prime}(1) \equiv \phi>0$.

We assume that the Rotemberg price adjustment costs faced by firms depend on the ratio 
between the new reset price and the one set in the previous period, adjusted by a geometric average of gross steady state inflation and past inflation. Specifically, the price adjustment costs that enter the maximization problem of the firm in (14) are now assumed to equal:

$$
\frac{\zeta}{2}\left(\frac{P_{t+s, i}}{\left(1+\pi_{t+s-1}\right)^{\psi}(1+\bar{\pi})^{1-\psi} P_{t+s-1, i}}-1\right)^{2} Y_{t+s},
$$

where $\bar{\pi}$ denotes steady-state inflation and $\psi$ denotes the degree of indexation to past inflation. This specification gives rise to a backward looking term in the NK Phillips curve.

Following Sala, Soderstrom, and Trigari (2013), we assume that the hiring friction cost function is

$$
g\left(A_{t}, H_{t, i}, N_{t, i}, \breve{K}_{t, i}\right)=\frac{e}{2} q_{t}^{-\eta^{q}}\left(\frac{H_{t, i}}{N_{t, i}}\right)^{2} f_{t, i} .
$$

where $q_{t}=\frac{H_{t}}{V_{t}}$ and $H_{t}, V_{t}$ are aggregates.

When $\eta^{q}=0$ the function reduces to

$$
g_{t, i}=\frac{e}{2}\left[\frac{H_{t, i}}{N_{t, i}}\right]^{2} f_{t, i}
$$

which is the same as in (12), where all friction costs depend on the firm-level hiring rate and are not associated with the number of vacancies per se. In this case, marginal hiring costs are not affected by the probability that a vacancy is filled.

When instead $\eta^{q}=2$ the function becomes

$$
g_{t}=\frac{e}{2}\left[\frac{V_{t, i}}{N_{t, i}}\right]^{2} f_{t, i}
$$

and is only associated with posting vacancies. In this case, an increase in the vacancy filling rate $q_{t}$ decreases the marginal cost of hiring. For intermediate values of $\eta^{q} \in(0,2)$, the specification in (38) allows for both hiring rates and vacancy rates to matter for the costs of hiring. ${ }^{22}$

As for the household, we now assume external habits in consumption, meaning that the preferences of a household indexed by $j$ are described by the following utility function:

$$
U_{t, j}=\ln \left(C_{t, j}-\vartheta C_{t-1}\right)-\chi \frac{N_{t, j}^{1+\varphi}}{1+\varphi}
$$

where $\vartheta \in[0,1)$ is the habit parameter.

We remove the assumption that wages are bilaterally renegotiated in every period, thereby abandoning the intra-firm bargaining protocol and the underlying assumption that firms correctly anticipate the impact of their hiring and capital rental policy on the negotiated wage. We

\footnotetext{
${ }^{22}$ This can be seen immediately by rewriting the friction cost function in (38) as $g_{t}=\frac{e}{2}\left(\frac{V_{t}}{N_{t}}\right)^{\eta^{q}}\left(\frac{H_{t}}{N_{t}}\right)^{2-\eta^{q}} f_{t}$
} 
instead assume wage rigidity in the form of a Hall (2005) type wage norm:

$$
\frac{W_{t}}{P_{t}}=\omega \frac{W_{t-1}}{P_{t-1}}+(1-\omega) \frac{W_{t}^{N A S H}}{P_{t}}
$$

where $\omega$ is a parameter governing real wage stickiness, and $W_{t}^{N A S H}$ denotes the reference wage

$$
W_{t}^{N A S H}=\arg \max \left\{\left(V_{t}^{N}\right)^{\gamma}\left(Q_{t}^{N}\right)^{1-\gamma}\right\}
$$

This simple wage-setting rule allows for targeting the persistence of the real wage data series in the calibration of the model.

\subsection{Calibration}

The model is calibrated following the same steps as in sub-section 4.1. The parameter values for the friction cost scale parameter $e$ and the bargaining power $\gamma$ are set so as to hit the same targets as in the calibration of the simple model. The parameter of the matching function $l$ is calibrated to target a vacancy filling rate of 70\%, as in Den Haan, Ramey and Watson (2000). The scale parameter in the utility function $\chi$ is no longer normalized to equal one, but is set so as to target the same replacement ratio of the opportunity cost of work over the marginal revenue product $(77 \%)$, as implied by the benchmark calibration in sub-section 4.1 . All other parameter values that are common to the simple model are set to the same value reported in Table 1. As for the new parameters, the investment adjustment cost parameter $\phi$ is set to 2.5 , and the habit parameter to $\vartheta=0.8$, reflecting the estimate by Christiano, Eichenbaum and Trabandt (2016). The parameter governing trend inflation is set to $\bar{\pi}=0.783 \%$, which corresponds to the average of the US GDP deflator over the calibration period. Given that, the value of the discount factor $\beta$, is set so as to match a $1 \%$ nominal rate of interest. We set the degree of indexation to a moderate value of $\psi=0.5$, and the parameter governing wage rigidity to $\omega=0.8$, as in Chistoffel and Linzert (2010), in order to match the persistence of the US real wage data. Finally, we set the elasticity of the hiring friction function $\eta^{q}$ to 0.49 , which is value estimated by Sala, Soderstrom, and Trigari (2013) for the US economy. We note that this estimate implies a stronger influence of vacancy filling rates in hiring costs than what would be implied by the micro-evidence reported by Silva and Toledo (2009), which would map into a coefficient of $\eta^{q}$ of 0.145 . Parameter values and calibration targets for the extended model are reported in Table 2.

\section{Table 2}

\subsection{Results}

\subsubsection{The Interaction of Hiring Frictions and Price Frictions}

Technology shocks. Figure 3 reports impulse responses for a technology shock obtained under the benchmark parameterization with moderate friction costs, $e=1.85$ (the green solid line), 
and an alternative parameterization with a higher, but still reasonable friction cost (the purple broken line). For the "high" friction case we assume a value of $e=5$, which implies average hiring costs equal to one and a half months of wages as in Silva and Toledo (2009), and marginal hiring cost equal to about three months of wages, which is still below the upper bound for hiring costs reported by Blatter et al. (2016).

\section{Figure 3}

Figure 3 shows that the lower calibration of friction costs is not sufficient to turn the response of employment from negative to positive on the impact of the technology shock. A larger friction parameterization instead can. Yet, most strikingly, increasing hiring costs implies a much stronger expansionary response of employment, investment, output and consumption, which increase over the impulse response horizon showing persistent, hump-shaped dynamics. This counterintuitive result, whereby higher frictions magnify the response of real variables in a NK model, is in accordance with the discussion of the mechanism presented in sub-section 5.1, whereby labor market frictions increase the sensitivity of the shadow value of output to changes in relative prices. As a result, higher hiring frictions generate a stronger response of employment and production on the supply side, and a stronger reaction of consumption and investment on the demand side. Summing up, Figure 3 shows that moderate changes of hiring frictions in the extended model with price frictions produce dramatic effects on the transmission of technology shocks.

A complementary and insightful approach to identify and visualize the effect of the interaction between price frictions and hiring frictions is to show how price frictions affect the transmission of technology shocks in a model with hiring frictions. The natural focus, in this context, is on the behavior of unemployment, which has sparked a large literature since Shimer (2005), as discussed in Section 2. We do so in Figure 4, where we compare the impulse responses obtained under the same "high" hiring friction case reported in Figure 3 (traced out by the purple broken lines), with the otherwise identical model where we shut down price frictions, i.e. we set $\zeta \simeq 0$ (this is traced out by the light blue solid lines).

In Figure 4 we label the rigid price model as $\mathrm{NK}+\mathrm{L}$ Frictions, and the flexible price model as NC + L Frictions.

\section{Figure 4}

Because the latter is effectively a rich specification of the DMP model with capital, Figure 4 allows us to pin down the effects of introducing price frictions into this DMP benchmark. The figure reveals that the mechanism produces strong amplification of unemployment to the underlying TFP shock, with an impact elasticity around 7 and a peak elasticity around 10 in the presence of both hiring frictions and price frictions. This compares with an impact - and peak - elasticity around 2 under flexible prices. Indeed, the hump-shaped impulse response of unemployment to technology shocks disappears when prices are made fully flexible. Hence, introducing price frictions into a model with hiring frictions generates both volatility and endogenous persistence in the response of unemployment to technology shocks. The mechanism, 
once again, is the one discussed in sub-section 5.1: price rigidities increase the sensitivity of the shadow value of output to the technology shock. In turn, when hiring costs are internal, shadow values affect the incentives for job creation by inducing changes in the marginal cost of hiring. If the friction costs are large enough, the fall in shadow values induced by an expansionary technology shock, decreases the marginal cost of hiring by more than the decline in marginal profits, amplifying the increase in hiring.

It is worth noting that in the case where there are no price frictions (the light blue line), the model lacks amplification, despite the high level of real wage rigidities imposed in the calibration $(\omega=0.8)$. Indeed, the response of labor market variables to technology shocks in this model is smoothed by the procyclical opportunity cost of work, $\chi C_{t} N_{t}^{\varphi}$. Using detailed microdata, Chodorow-Reich and Karabarbounis (2016) provide evidence that the opportunity cost of work is indeed procyclical; they show that under this assumption many leading models of the labor market, including models with rigid wages, fail to generate amplification, irrespective of the level of the opportunity cost. The amplification of labor market outcomes generated in our model by the interaction of hiring and price frictions is instead robust to the procyclicality of the opportunity cost of work.

Monetary policy shocks. In analogy with Figure 3, Figure 5 reports impulse responses for a monetary policy shock obtained under the same "low" and "high" parameterizations of friction costs.

\section{Figure 5}

The impulse response analysis reveals that at the lower level of friction costs (green line), an expansionary monetary policy shock produces real effects, reducing the real rate of interest and increasing output, consumption, employment, investment, and real wages. At the higher level of friction costs instead (purple line), monetary policy shocks still produce real effects, but in the opposite direction.

These results are consistent with those that were obtained with the simple model of Section 3. As explained in sub-section 5.2, increasing hiring friction costs implies that the marginal cost of hiring becomes more sensitive to the increase in the shadow value. Increasing friction costs reduces the effectiveness of monetary policy until a threshold where most real variables do not respond on the impact of the shock. Beyond that threshold, the NK propagation of monetary policy shocks is reversed, with a negative shock to the nominal interest rate leading to a contraction in real economic activity.

In the "high" frictions case, the incentives for job creation fall on the impact of an expansionary monetary shock, so production must also fall. Given this fall in supply, in equilibrium, the shadow value $\Psi_{t}$ must increase strongly so as to raise the current price level $P_{t}$ and thereby curb the aggregate demand stimulus generated by the fall in the interest rate. In the "low" frictions case instead, the aggregate demand stimulus is absorbed by an increase in output supply, and as a result the shadow value of output, and therefore output prices, do not need to increase 
as much. ${ }^{23}$ In turn, the stronger response of current inflation in the "high" frictions case will offset, via the Taylor rule, the exogenous shock to the nominal interest rate, dampening the fall in the nominal interest rate and hence in the real rate.

We emphasize that the parameterization of friction costs underlying the purple line, which corresponds to the survey evidence of hiring costs reported in Silva and Toledo (2009), is a perfectly reasonable parameterization, and is labeled in Figures 3 and 5 as "high" friction cost purely for comparative reasons. So the bottom line of the analysis presented in this Section, is that changing hiring costs within a reasonable, moderate range of parameterizations, has dramatic implications for the propagation of shocks even in a relatively rich specification of the model.

\subsubsection{Internal vs. External Costs of Hiring}

The medium-scale model considered so far allows for both external and internal costs to affect the propagation of shocks. The results of the previous subsection have shown that for a reasonable combination of these costs, the interaction of hiring frictions and price frictions matters for the transmission of both technology and monetary shocks. Here we show how the propagation of shocks changes when we exclude internal costs altogether. This exercise is convenient to relate to a literature, which has predominantly focussed on external costs of hiring. Namely, we report the impulse responses obtained in the "low" vs. "high" friction cases, for the case of $\eta^{q}=2$, which implies that hiring frictions are entirely driven by external vacancy rates. The results are shown in Figures 6 and 7 for technology shocks and monetary policy shocks, respectively.

\section{Figures 6 and 7}

Both Figures show that in the special case where internal costs are set to zero, hiring frictions do not matter much for the transmission of shocks. Hence, the model recovers the result surveyed by Galí (2011), but as the outcome of a very specific parameterization.

To understand why the mechanism presented in Section 5 breaks down in the case of $\eta^{q}=2$ consider the FOC for hiring,

$$
Q_{t}^{N}=\Psi_{t} g_{H, t}
$$

where $g_{H, t}$ now becomes

$$
g_{H, t}=e \frac{1}{q_{t}} \frac{V_{t}}{N_{t}} \frac{f\left(z_{t}, N_{t}, \breve{K}_{t}\right)}{N_{t}} .
$$

\footnotetext{
${ }^{23}$ We note that the response of the real marginal cost is not persistent in the "high" frictions case, even in the presence of wage rigidities. This is because the marginal cost is mostly explained by the frictional component, i.e. the third term on the RHS of eq.(21), which is not persistent, being a quasi-first-difference of $Q_{t}^{N}$. This result is in contrast to the dynamics generated by the canonical, frictionless NK model, where marginal costs are only driven by the first term in eq.(21), the labor share. In this frictionless model, real wage rigidities directly induce persistence in the real wage and therefore in the marginal cost. In the "low" e parameterization, the contribution of the frictional component to the variation of marginal costs is relatively less important. This model is thus relatively closer to the NK frictionless benchmark, and therefore the real marginal cost will reflect more closely the response of the labor share. In this "low" frictions case, wage rigidities imply that the response of marginal costs will also be persistent.
} 
As before, a fall in the shadow value $\Psi_{t}$ engendered by an expansionary technology shock still decreases the marginal cost of hiring thereby increasing vacancy creation. But the congestion externalities in the matching function imply a strong fall in the vacancy filling rate $q_{t}$, which in turn increases the marginal cost of hiring, offsetting the initial effect of $\Psi_{t}$. For lower values, i.e., values of $\eta^{q}$ less than 2, aggregate labor market conditions, expressed via $q_{t}$, matter less for the marginal cost of hiring, and the strong feedback effect of vacancy rates on the marginal cost of hiring is diluted.

\subsubsection{Output Costs vs. Pecuniary Costs of Hiring}

So far we have assumed that the hiring costs specified in eq.(38) are expressed in units of forgone output. Alternatively we could have assumed, following the convention in the literature, that hiring costs are pecuniary, meaning that they are specified in units of the composite good. In this case the production function (13) is simply

$$
Y_{i, t}=f\left(A_{t}, N_{t, i}, \breve{K}_{t, i}\right)
$$

and the maximization problem of the firm becomes

$$
\begin{aligned}
\max _{P_{t+s, i}, H_{t+s, i}, \breve{K}_{t+s, i}} E_{t} \sum_{s=0}^{\infty} & \Lambda_{t, t+s}\left\{\frac{P_{t+s, i}}{P_{t+s}} Y_{t+s, i}-\frac{W_{t+s}\left(\breve{K}_{t+s, i}, H_{t+s, i}, N_{t+s, i}\right)}{P_{t+s}} N_{t+s, i}-\frac{R_{t+s}^{K}}{P_{t+s}} \breve{K}_{t+s, i}\right. \\
& \left.-g\left(A_{t+s, i}, H_{t+s, i}, N_{t+s, i}, \breve{K}_{t+s, i}\right)-\frac{\zeta}{2}\left(\frac{P_{t+s, i}}{P_{t+s-1, i}}-1\right)^{2} Y_{t+s}\right\}
\end{aligned}
$$

subject to the technology constraint (42), the law of motion for employment (11) and the demand function (10).

The main implication of assuming pecuniary costs is that the first order condition for hiring becomes:

$$
Q_{t}^{N}=g_{H, t}
$$

which implies that the cost of the marginal hire is no longer affected directly by the shadow value of output $\Psi_{t}$.

This model with pecuniary costs does not generate reversals of the New Keynesian outcomes, unlike the model with output-costs. As explained in Section (5), if the marginal cost of hiring is not affected by fluctuations in the shadow value of output, the transmission mechanism is the standard New-Keynesian one.

Interestingly, we find that the model with pecuniary costs of output is prone to indeterminacy even for moderate values of hiring frictions. Specifically, for the parameter vector underlying our "high" friction cost calibration, which underpins the purple lines in Figures 3 to 5, the model with pecuniary costs does not satisfy the conditions for determinacy. The intuition for this indeterminacy is as follows. If firms expect aggregate demand to be high, they will hire more workers to increase production and meet this high level of demand. If prices are 
sticky and hiring costs are pecuniary, i.e., they are purchases of the composite good, the increase in the demand for hiring services stimulates aggregate demand. Hence, expectations of higher demand become self-fulfilling. If hiring costs are forgone output instead, higher hiring does not stimulate demand, and the model is not prone to indeterminacy. This implies that the conventional modelling of hiring costs as pecuniary costs, can only support equilibria where hiring frictions are sufficiently small. Thus, any estimation of such friction costs in general equilibrium can only deliver quantitatively small estimates.

\subsubsection{Variations in the Taylor Rule}

It is well known that in NK models the dynamics of the endogenous variables are sensitive to the precise parameterization of the Taylor rule coefficients. For instance, a positive technology shock implies that the same level of demand can be achieved with less labor, so everything else equal the demand for labor falls. But at the same time inflation also drops, inducing a fall in the nominal interest rate via the Taylor rule, which in turn offsets the tendency for employment to decline. In equilibrium, employment can rise or fall, depending on the endogenous response of interest rates.

So, in order to show that the offsetting effect of hiring frictions on the standard NK dynamics does not depend on the parameters of the Taylor rule, we have carried out the following robustness exercise.

We take as a benchmark the version of the extended model parameterized with comparatively high frictions, i.e. $e=5$. As discussed in the previous sub-section, under this parameterization an expansionary technology shock produces an increase in employment and an expansionary monetary policy shock produces a contraction in output. To show that these substantial results are a genuine manifestation of the offsetting effect of friction costs, and not an artifact of a specific Taylor rule, we inspect impulse responses obtained by randomizing the Taylor rule coefficients over a broad parameter space, leaving all other parameters fixed at the values reported in Table 2.

Specifically, we have generated 10,000 parameterization vectors, which differ only in the coefficients governing the Taylor rule. These parameter values are assigned by drawing randomly from uniform distributions defined over the support of $r_{y} \sim U(0,0.5), r_{\pi} \sim U(1.1,3)$ and $\rho_{r} \sim U(0,0.8)$. Our results indicate that output responded negatively on the impact of a monetary stimulus in every single parameterization, and the sign of the response was never overturned one year or two years after the impact. Similarly, on the impact of the technology shock instead, employment responded positively in every single parameterization. The sign of the response was not overturned after one year in any of the parameterizations and remained in positive territory, after two years, in $99.8 \%$ of the parameterizations.

\subsection{The Results in the Context of the Empirical Literature}

Our theoretical investigation has related to a grid of values in the joint space of price frictions and hiring frictions. It supports the full variety of results obtained in the empirical VAR and 
DSGE studies. This variety includes contradictory findings. Our model is able to account for them, when predicating the outcomes on values of $e$ and $\zeta$.

Technology Shocks. The New Classical model posits a key role for technology shocks in generating business cycles, with positive shocks leading to employment and output expansion; see, for example, Section 4 in King and Rebelo (1999). The seminal work by Galí (1999), which sparked a debate in the literature, was the first to identify a negative response of employment to total factor productivity (TFP) shocks. While Galí (2004) and others have provided more evidence in this direction, VAR analysis in Uhlig (2004), Christiano, Eichenbaum and Vigfusson (2004), Mertens and Ravn (2011), Alexopoulos (2011), and Sims (2011) found opposite results, pointing to a positive response of employment.

In a recent survey paper, Ramey (2016) lists almost 20 specifications of DSGE models and their results (see her Table 9). Four studies find that TFP shocks explain sizeable fractions of output fluctuations (in the range of $40 \%$ to $75 \%$ ), six studies document little effect (less than $10 \%$ explained), and the rest range from $12 \%$ to $30 \%$. In discussing the findings of these models and of the related VAR results, Ramey points to their contrasting findings. For example, in models without price rigidity, positive TFP shocks invariably raise hours of work and in models with price rigidity they invariably lower hours of work. In the latter case, technology shocks are unlikely to be an important source of economic fluctuations, as they cannot generate the positive co-movement between employment and output, which is characteristic of the business cycle. The current paper has shown that our modelling of hiring frictions does not constrain the sign of the response of hiring to technology shocks. This would give technology shocks a channel to matter for economic fluctuations, even in a DSGE model with price rigidities.

Monetary Policy Shocks. The standard, expansionary effects of a decrease in interest rates are consistent with a multitude of results in the VAR literature, which rely on a variety of identification schemes. Yet, the findings in Faust, Swanson and Wright (2004), Uhlig (2005), and Amir and Uhlig (2016) are consistent with the view that monetary policy produces small real effects or even no real effects. Table 1 in Ramey (2016) lists 11 specifications of DSGE models and their results. Only two studies find that these shocks explain sizeable fractions of output fluctuations, while the others document small effects (less than 10\% explained). Moreover, Ramey (2016) argues that relaxing the conventional assumption in VARs whereby prices and output cannot respond to the interest rate contemporaneously, leads to "puzzling" results, whereby an expansionary monetary policy shock seems to have significant contractionary effects. These results emerge using a variety of agnostic identification schemes. In the current paper we show that the model encompasses all these outcomes: (i) one can get small or no real effects to monetary policy in the case of no price frictions as well as in the case of baseline degrees of both price and hiring frictions; (ii) the real effect of monetary policy is more substantial with low hiring frictions and conventional price frictions; (iii) the real effect of monetary policy is overturned with sufficiently high hiring frictions, in the presence of price frictions.

Our Model and the Empirical Literature. Our model thus provides for a rationalization of a very diverse set of findings. In the light of our model, taking a stance on the conflicting VAR or empirical DSGE evidence can be rationalized as implicitly taking a stance on the degrees of 
price and hiring frictions.

\section{Conclusions}

This paper shows that hiring frictions matter in a significant way for business cycles, not only through wage setting mechanisms. Using a grid of plausible parameterizations, we have shown that hiring frictions are as important as price frictions for the propagation of shocks in New-Keynesian models. Hence, we conclude that New Keynesian modelling needs to recognize the importance of hiring frictions in the transmissions of shocks. At the same time, search and matching DMP modelling needs to recognize the importance of price frictions. The interactions of frictions are key.

Our model emphasizes the importance of the internal output cost of hiring, which appears to be the most empirically relevant source of hiring frictions in the micro-data. By changing the notion of hiring costs we were able to reverse the conclusions obtained in the literature, which found a negligible direct role for hiring frictions in business cycle models. Thus, we have shown that the precise nature of hiring frictions is key for the transmission of shocks.

These results highlight the importance of empirical estimates. There is a need for research exploring the joint optimality equations for firms hiring and pricing. This may be undertaken through empirical examination of the optimality equations of the firm, at the aggregate, sectorial, and firm levels. Currently, such empirical evidence is scant or non-existent, especially at the dis-aggregated levels. The scarcity of research on this topic is striking, particularly when compared to the vast literature that has measured the frequency of price adjustments. ${ }^{24}$ Indeed, most of the empirical research in this field has focused on measuring price rigidities under the prevalent belief that this is a necessary statistic to gauge the strength of the New-Keynesian mechanism. On the other hand, the empirical literature has neglected the measurement of hiring frictions, under the belief that these frictions are small, and not so important for our understanding of the business cycle.

Our results indicate that if hiring frictions are more than tiny, though still moderate, the precise degree of price rigidity is less relevant, if not irrelevant, in the propagation of shocks to real variables. For higher, yet not implausible values of frictions costs, the conventional New Keynesian propagation mechanism is even turned upside-down. Therefore, the Macro literature needs a correct assessment of hiring costs in conjunction with price frictions to gauge the propagation of shocks at business cycle frequencies. We leave this important task for future research.

\section{References}

[1] Alexopoulos, M. (2011). "Read All About It! What Happens Following a Technology Shock," American Economic Review 101, 1144-1179.

\footnotetext{
${ }^{24}$ See, for example, the recent sectorial study of price frictions in De Graeve and Walentin (2015) and the references therein.
} 
[2] Alexopoulos, M. and T. Tombe (2012). "Management Matters," Journal of Monetary Economics 59, 269-285.

[3] Amir A. P. and H. Uhlig (2015). "Sign Restrictions in Bayesian FAVARs with an Application to Monetary Policy Shocks," NBER Working paper 21738.

[4] Andolfatto, D. (1996). "Business Cycles and Labor-Market Search," American Economic Review 86,1 112-132.

[5] Barro, R.J. (1977). “Long-Term Contracting, Sticky Prices, and Monetary Policy.” Journal of Monetary Economics 3: 305-16.

[6] Basu, S. and J. Fernald, (1997). "Returns to Scale in US Production: Estimates and Implications," Journal of Political Economy, 105(2), 249-83.

[7] Blanchard, O. and J. Galí, (2010). "Labor Markets and Monetary Policy: A New Keynesian Model with Unemployment," American Economic Journal: Macroeconomics 2(2), 1-30.

[8] Blatter M., S. Muehlemann, S. Schenker, and S.C. Wolterd (2016). “Hiring Costs for Skilled Workers and the Supply of Firm-Provided Training," Oxford Economic Papers, 68, 1, 238-257.

[9] Brugemann, B., P. Gautier, and G. Menzio, (2017). “Intra Firm Bargaining and Shapley Values," working paper.

[10] Burnside, C. (1996). "Production Function Regressions, Returns to Scale, and Externalities," Journal of Monetary Economics 37, 177-201.

[11] Cahuc, P., F. Marque, and E. Wasmer (2008). "A Theory Of Wages And Labor Demand With Intra-Firm Bargaining And Matching Frictions," International Economic Review 49(3), 943-72.

[12] Chetty, R., A. Guren, D. Manoli, and A. Weber (2013). “Does Indivisible Labor Explain the Difference between Micro and Macro Elasticities? A Meta-Analysis of Extensive Margin Elasticities," NBER Macroeconomics Annual 2012, Volume 27: 1-56.

[13] Chodorow-Reich, G., and L. Karabarbounis (2016). "The Cyclicality of the Opportunity Cost of Employment," Journal of Political Economy 124,6,1563 - 1618.

[14] Christiano, L. J., M.S. Eichenbaum, and M. Trabandt (2016). “Unemployment and Business Cycles," Econometrica 84, 4, 1523-1569.

[15] Christiano, L. J., M.S. Eichenbaum, and R. Vigfusson (2004). "The Response of Hours to a Technology Shock: Evidence Based on Direct Measures of Technology," Journal of the European Economic Association 2(2-3), 381-395. 
[16] Christiano, L. J., M. Trabandt, and K.Walentin (2011). “Introducing Financial Frictions and Unemployment Into a Small Open Economy Model," Journal of Economic Dynamics and Control 35,1999-2041.

[17] Christoffel, K. and T. Linzert (2010). “The Role of Real Wage Rigidity and Labor Market Frictions for Inflation Persistence," Journal of Money, Credit and Banking 42(7), 14351446.

[18] Cochrane, J.H. (2005). Asset Pricing, Revised Edition, Princeton University Press.

[19] Cochrane, J.H. (2008). "Financial Markets and the Real Economy, " Chapter 7 in R.Mehra (Ed.) Handbook of the Equity Risk Premium 237-325, North-Holland. Amsterdam.

[20] Coles, M. and D. Mortensen (2016). "Equilibrium Labor Turnover, Firm Growth and Unemployment," Econometrica 84, 347-363.

[21] Costain, J. and M. Reiter (2008). “Business Cycles, Unemployment Insurance, and the Calibration of Matching Models," Journal of Economic Dynamics and Control 32 (4),1120-55.

[22] Davis, S. J. and J.Haltiwanger (1999). "Gross Jo b Flows," in Chapter 41 in O.Ashenfelter and D. Card (eds.) Handbook of Labor Economics Vol. 3, 2711-2805, North Holland, Amsterdam.

[23] Davis, S. J. and J.Haltiwanger (2014). "Labor Market Fluidity and Economic Performance," Federal Reserve Bank of Kansas City, Jackson Hole Economic Policy Symposium.

[24] Davis, S. J., J.Haltiwanger, and S.Schuh (1996). Job Creation and Destruction, MIT Press, Cambridge.

[25] De Graeve. F, and K. Walentin (2015). "Refining Stylized Facts from Factor Models of Inflation," Journal of Applied Econometrics 30, 1192-1209.

[26] Den Haan W.J. , G. Ramey, and J.Watson (2000). “Job Destruction and Propagation of Shocks," American Economic Review 90 , 482-498.

[27] Faust, J., E. T. Swanson, and J. H. Wright (2004). "Identifying VARS Based on High Frequency Futures Data," Journal of Monetary Economics 51, 6, 1107-113.

[28] Furlanetto, F. and N. Groshenny (2016). “Mismatch Shocks and Unemployment During the Great Recession," Journal of Applied Econometrics 31, 7, 1197-1214.

[29] Galí J. (1999). “Technology, Employment, and the Business Cycle: Do Technology Shocks Explain Aggregate Fluctuations?," American Economic Review 89(1), 249-271.

[30] Galí J. (2004). “On the Role of Technology Shocks as aSsource of Business Cycles: Some New Evidence," Journal of the European Economic Association 2(2-3),372-380. 
[31] Galí, J. (2011). "Monetary Policy and Unemployment," Chapter 10 in B.M. Friedman and M.Woodford (eds.) Handbook of Monetary Economics Vol. 3A, 487-546, North Holland, Amsterdam.

[32] Galí, J. (2015). Monetary Policy, Inflation and the Business Cycle: An Introduction to the New Keynesian Framework, 2nd edition. Princeton University Press, Princeton.

[33] Galí, J. and M. Gertler (2007). "Macroeconomic Modeling for Monetary Policy Evaluation," Journal of Economic Perspectives 21 (4): 25-45.

[34] Gertler, M., L. Sala, and A. Trigari (2008). "An Estimated Monetary DSGE Model With Unemployment and Staggered Nominal Wage Bargaining," Journal of Money, Credit and Banking 40, 1, 713-64.

[35] Giannoni, M.P. and M. Woodford (2005). “Optimal Inflation-Targeting Rules," Chapter 3 in B.S.Bernanke and M.Woodford (eds.) The Inflation Targeting Debate, 93-162, University of Chicago Press, Chicago.

[36] Hall, R. E. (2005) “Employment Fluctuations with Equilibrium Wage Stickiness," American Economic Review, 95(1), 50-65.

[37] Khan, A. and J. Thomas (2008). "Idiosyncratic Shocks and the Role of Nonconvexities in Plant and Aggregate Investment Dynamics," Econometrica 76, 2, 395-436.

[38] King, R.G. and S.T. Rebelo (1999). "'Resuscitating Real Business Cycles," in J. B. Taylor \& M. Woodford (ed.s), Handbook of Macroeconomics, volume 1, chapter 14, 927-1007 Elsevier.

[39] King, R.G. and J. Thomas (2006). "Partial Adjustment Without Apology," International Economic Review 47, 3, 779-809.

[40] Krause, M.U., D. Lopez-Salido and T.A. Lubik (2008). "Inflation Dynamics with Search Frictions: A Structural Econometric Analysis," Journal of Monetary Economics 55, 892916.

[41] Kuester, K. (2010). "Real Price and Wage Rigidities with Matching Frictions," Journal of Monetary Economics, 57(4),466-477.

[42] Ljungqvist, L. and T. Sargent (2017). "The Fundamental Surplus," American Economic Review 107(9), 2630-2665.

[43] Lucas, R. E, Jr and E.C. Prescott, (1971). “Investment Under Uncertainty,” Econometrica 39(5), 659-81.

[44] Mertens, K., Ravn, M.O., (2011). “Technology-Hours Redux: Tax Changes and the Measurement of Technology Shocks" in R.Clarida and F. Giavazzi (eds.) NBER International Seminar on Macroeconomics 2010. Chapter 2, 41-76, University of Chicago Press. 
[45] Merz, M. (1995). "Search in the Labor Market and the Real Business Cycle" Journal of Monetary Economics 36, 2, 269-300.

[46] Merz, M. and E. Yashiv (2007). "Labor and the Market Value of the Firm," American Economic Review 97, 1,419-31.

[47] Nekarda, C. and V. Ramey (2013). "The Cyclical Behavior of the Price-Cost Markup,", NBER Working Paper No. 19099.

[48] Pissarides, C.A. (2000). Equilibrium Unemployment Theory, The MIT Press, 2nd edition, Cambridge, MA.

[49] Pissarides, C.A. (2009). "The Unemployment Volatility Puzzle: Is Wage Stickiness the Answer?," Econometrica, 77(5), 1339-1369.

[50] Ramey, V. (2016). "Macroeconomic Shocks and Their Propagation," in J.B. Taylor and H.Uhlig (eds). Handbook of Macroeconomics, vol. 2A, Chapter 2, 71-162. North-Holland, Amsterdam.

[51] Rogerson, R. and R. Shimer (2011). "Search in Macroeconomic Models of the Labor Market," in O.Ashenfelter and D.Card (eds.) Handbook of Labor Economics Vol 4A, North Holland, Amsterdam.

[52] Rotemberg, J. (1982). "Monopolistic Price Adjustment and Aggregate Output," Review of Economic Studies 49, 517-31.

[53] Sala, L., U. Söderstrom, and A. Trigari (2013).“Structural and Cyclical Forces in the Labor Market during the Great Recession: Cross-Country Evidence" in F.Giavazzi and K.D. West (eds.) NBER International Seminar on Macroeconomics 2012, Chapter 8, 345- 404, University of Chicago Press.

[54] Sbordone, A.M. (2005). “Do Expected Future Marginal Costs Drive Inflation Dynamics?" Journal of Monetary Economics 52, 1183-1197.

[55] Shimer, R. (2005). "The Cyclical Behavior of Equilibrium Unemployment and Vacancies," American Economic Review 95, 1, 25-49.

[56] Silva, J., and M. Toledo (2009). "Labor Turnover Costs and the Cyclical Behavior of Vacancies and Unemployment," Macroeconomic Dynamics 13 (S1), 76-96.

[57] Sims, E.R. (2011). "Permanent and Transitory Technology Shocks and the Behavior of Hours: A Challenge for DSGE Models," University of Notre Dame, mimeo.

[58] Smets, F. and R. Wouters, (2007). "Shocks and Frictions in US Business Cycles: A Bayesian DSGE Approach," American Economic Review 97(3), 586-606.

[59] Uhlig, H. (2004). “Do Technology Shocks Lead to a Fall in Total Hours Worked?" Journal of the European Economic Association . 2(2-3), 361-371. 
[60] Uhlig, H. (2005). "What Are The Effects of Monetary Policy on Output? Results from an Agnostic Identification Procedure," Journal of Monetary Economics 52 (2) 381-419.

[61] Walsh, C. (2005). “Labor Market Search, Sticky Prices, and Interest Rate Rules," Review of Economic Dynamics 8, 829-849.

[62] Woodford, M. (2003). Interest and Prices: Foundations of a Theory of Monetary Policy. Princeton University Press, Princeton.

[63] Woodford, M. (2005). 'Firm-Specific Capital and the New Keynesian Phillips Curve," International Journal of Central Banking 1,2,1-46.

[64] Yashiv, E. (2000). "The Determinants of Equilibrium Unemployment," American Economic Review 90,5,1297-1322.

[65] Yashiv, E. (2016). "Capital Values and Job Values," Review of Economic Dynamics,19, 1, 190-209.

[66] Yashiv, E. (2017). “Hiring and Investment Interactions Over the Business Cycle,” working paper. 


\section{Appendix A \\ Solving for the Wage with Intrafirm Bargaining}

In this Appendix we follow Cahuc, Marque, and Wasmer (2008). We rewrite below for convenience the wage sharing rule consistent with wage bargaining as derived in equation (23):

$$
(1-\gamma) V_{t, i}^{N}=\gamma Q_{t, j}^{N}
$$

where we make use of subscripts $i$ and $j$ to denote a particular household $i$ and firm $j$ bargaining over the wage $W_{j t}$. Substituting (7) and (18) into the above equation one gets:

$$
\begin{gathered}
\gamma\left\{\left[\Psi_{t, j}\left(f_{N, t, j}-g_{N, t, j}\right)-\frac{W_{t, j}}{P_{t}}-\frac{W_{N, t, j}}{P_{t}} N_{t, j}\right]+\left(1-\delta_{N}\right) E_{t} \Lambda_{t, t+1} Q_{t+1, j}^{N}\right\}= \\
(1-\gamma)\left[\frac{W_{t, j}}{P_{t}}-\chi N_{t, i}^{\varphi} C_{t}-\frac{x_{t}}{1-x_{t}} V_{t, i}^{N}+\left(1-\delta_{N}\right) E_{t} \Lambda_{t, t+1} V_{t+1, i}^{N}\right] .
\end{gathered}
$$

Using the sharing rule in (44) to cancel out the terms in $Q_{t+1, j}^{N}$ and $V_{t+1, i}^{N}$ we obtain the following expression for the real wage:

$$
\frac{W_{t, j}}{P_{t}}=\gamma \Psi_{t, j}\left(f_{N, t, j}-g_{N, t, j}\right)-\gamma \frac{W_{N, t, j}}{P_{t}} N_{t, j}+(1-\gamma)\left[\chi C_{t} N_{t, i}^{\varphi}+\frac{x_{t}}{1-x_{t}} \frac{\gamma}{1-\gamma} Q_{t}^{N}\right] .
$$

Ignoring the terms in square brackets, which are independent of $N_{t, j}$ and can therefore be treated as a constant, and dropping all subscripts from now onward with no risk of ambiguity, we can rewrite the above equation as follows:

$$
W_{N}+\frac{1}{\gamma N} W-P \Psi\left(\frac{f_{N}}{N}-\frac{g_{N}}{N}\right)=0
$$

The solution of the homogeneous equation, $W_{N}+\frac{1}{\gamma N} W=0$, is

$$
W(N)=C N^{-\frac{1}{\gamma}},
$$

where $C$ is a constant of integration of the homogeneous equation. Assuming that $C$ is a function of $\mathrm{N}$ and deriving (47) w.r.t. $N$, yields:

$$
W_{N}=C_{N} N^{-\frac{1}{\gamma}}-\frac{1}{\gamma} C N^{-1-\frac{1}{\gamma}} .
$$

Substituting (47) and (48) into (46) one gets:

$$
C_{N}=N^{\frac{1-\gamma}{\gamma}} P \Psi\left(f_{N}-g_{N}\right) .
$$

Integrating (49) yields:

$$
C=P \Psi \int_{0}^{N} z^{\frac{1-\gamma}{\gamma}}\left(f_{z}-g_{z}\right) d z+D
$$


where $D$ is a constant of integration. Let's solve for the two integrals in $f_{z}$ and $g_{z}$, one at a time. Assuming that $f(A z, K)=A z^{\alpha} K^{1-\alpha}$, we can write:

$$
P \Psi \int_{0}^{N} z^{\frac{1-\gamma}{\gamma}} f_{z} d z=P \Psi \alpha \frac{\gamma}{1-\gamma(1-\alpha)} A N^{\frac{1-\gamma(1-\alpha)}{\gamma}} K^{1-\alpha}
$$

Given our assumptions on the functional form of $g$ as in (12), the function $g_{N}$ can be rearranged as follows:

$$
g_{N}=-A K^{1-\alpha} e H^{2} N^{\alpha-3}+\alpha A K^{1-\alpha} \frac{e}{2} H^{2} N^{\alpha-3} .
$$

Integrating the first term in the RHS of the above equation yields:

$$
P \Psi \int_{0}^{N} z^{\frac{1-\gamma}{\gamma}} A K^{1-\alpha} e H^{2} z^{\alpha-3} d z=P \Psi e H^{2} A K^{1-\alpha} \frac{\gamma}{1-\gamma+\gamma(\alpha-2)} N^{\frac{1-\gamma+\gamma(\alpha-2)}{\gamma}},
$$

Integrating the second term on the RHS of equation (52) yields:

$$
-P \Psi \int_{0}^{N} z^{\frac{1-\gamma}{\gamma}} \alpha A K^{1-\alpha} \frac{e}{2} H^{2} z^{\alpha-3} d z=-P \Psi \frac{e}{2} H^{2} \alpha A K^{1-\alpha} \frac{\gamma}{1-\gamma+\gamma(\alpha-2)} N^{\frac{1-\gamma+\gamma(\alpha-2)}{\gamma}} .
$$

Denoting $A_{1} \equiv \frac{\gamma}{1-\gamma(1-\alpha)}$ and $A_{2} \equiv \frac{\gamma}{1-\gamma+\gamma(\alpha-2)}$, we can now rewrite (50) as follows:

$$
C=D+P \Psi A K^{1-\alpha}\left[\alpha A_{1} N^{1 / A_{1}}+\left(1-\frac{\alpha}{2}\right) H^{2} A_{2} N^{1 / A_{2}}\right] .
$$

Plugging (55) into (47) one gets:

$$
W(N)=D N^{-\frac{1}{\gamma}}+P \Psi A K^{1-\alpha}\left\{\alpha A_{1} N^{\alpha-1}+\left(1-\frac{\alpha}{2}\right) e H^{2} A_{2} N^{\alpha-3}\right\} .
$$

In order to eliminate the constant of integration $D$ we assume that $\lim _{N \rightarrow 0} N W(N)=0$. The solution to (45) therefore is:

$$
\begin{gathered}
\frac{W_{t}}{P_{t}}=\gamma \Psi_{t} A_{t} K_{t-1}^{1-\alpha}\left\{\frac{\alpha N_{t}^{\alpha-1}}{1-\gamma(1-\alpha)}+\left(1-\frac{\alpha}{2}\right) \frac{e H_{t}^{2} N_{t}^{\alpha-3}}{1-\gamma+\gamma(\alpha-2)}\right\} \\
+(1-\gamma)\left[\chi C_{t} N_{t}^{\varphi}+\frac{x_{t}}{1-x_{t}} \frac{\gamma}{1-\gamma} Q_{t}^{N}\right] .
\end{gathered}
$$




\section{Appendix B \\ Impulse Responses for the Simple Model}

\section{Technology Shocks}

Figure B1 plots the full-horizon impulse responses to a positive technology shock in the following four versions of the model: (i) the model with both frictions - the NK model embodying price frictions together with hiring frictions (discussed in the calibration above, traced out by green lines); (ii) the NC model with hiring costs; this is obtained by setting a level of price frictions close to zero, i.e. $\zeta \simeq 0$, while maintaining hiring frictions as in the baseline calibration (traced out by blue lines); (iii) the standard NK model obtained by maintaining a high degree of price frictions, i.e. $\zeta=120$, but setting hiring costs close to zero, i.e. $e \simeq 0$ (traced out by red lines); (iv) the standard NC model with no frictions obtained by setting $\zeta \simeq 0$ and $e \simeq 0$ (traced out by black lines).

\section{Figure B1}

We emphasize that this simple model is geared to explain a mechanism, and not to get empirical magnitudes or fit that are comparable to VAR outcomes; in Section (6) we look at an extended model and explore robustness of our mechanism in a richer framework.

In the NC model with no frictions (model $i v$, the black line) the impulse responses are the usual NC-type responses with employment, capital and output increasing following a positive technological innovation. Adding hiring frictions to the NC model (model ii, blue line) generates a mild smoothing in the response of real variables. Independently of hiring frictions, in the NC models, the shadow value of output does not respond.

When price frictions are included, the shadow value of output falls following a positive technology shock. Quantitatively, this fall is very similar in the NK model without (model iii, red line) and with (model $i$, green line) hiring frictions. Yet, on the impact of the technology shock, the response of hiring, employment, and output in the standard NK benchmark is markedly different with respect to the NK model with frictions and the NC models. In Figure B1 there is a clear difference between the red lines and all other lines. Indeed, employment contracts substantially in this model, which attenuates considerably the initial response of output. Because the shadow value of output is not persistent in this simple NK model, and because the different response of real variables across models is largely driven by their different sensitivity to the shadow values, the difference in the responses beyond the first quarter are less pronounced. So over time, the pattern of responses is similar across the four model specifications, pointing to a rise in employment, capital, and output, as well as in real wages.

Most importantly, the figure shows that the impulse responses of hiring, employment, investment, capital and output are virtually identical in the two models with hiring frictions (models $i$ and $i i$ above; the green and blue lines in the figure); this implies that in the presence of the hiring frictions assumed in the calibration, the response of these real variables is independent of the level of price frictions. Notably, employment rises following a positive technology shock. 
The magnitude of the real rate increase that follows a positive technology shock is very similar across models, which implies that the response of consumption is also similar. Hence, differences in the response of output across models are mostly explained by the different response of investment. Finally, we emphasize that adding hiring frictions onto the NK benchmark generates a smoother reaction in real wages, meaning that these frictions generate endogenous wage rigidity.

\section{Monetary Policy Shocks}

Figure B2a plots impulse responses to an i.i.d. expansionary monetary policy shock in the same four versions of the model discussed above.

\section{Figure B2a}

The results show that in the absence of price frictions, money is neutral, independently of labor market frictions. In the NK benchmark (model iii) instead, the monetary policy shock has real effects, which lead to an increase in employment, investment, output and real wages. ${ }^{25}$ Most importantly, real variables respond very differently in the NK model without (model iii, red line) and with (model $i$, green line) hiring frictions: introducing these frictions virtually eliminates all real effects of monetary policy shocks, so that for all real variables except the shadow value of output (real marginal cost) and wages, the response of the NK model with hiring frictions is indistinguishable from the response of the NC benchmark.

The irrelevance of price frictions in the transmission of shocks does not arise because marginal hiring cost are large, and hence quantities cannot move. Indeed, as noted in the case of technology shocks, in the absence of price frictions the real variables respond strongly, even in the presence of hiring frictions. Employment, and therefore output, do not respond because of the following mechanism: when hiring costs are forgone output, a change in shadow prices affects both the marginal revenue product and the marginal cost of hiring, in a way that leaves the marginal incentives to hire unchanged (at the calibrated value of $e$ ). Indeed, both the output that is produced by the marginal worker and the output that is forgone by incurring marginal recruitment costs are expressed in the same units of good output. Hence a change in the shadow value of output will affect not just the marginal revenue product, but also the real marginal cost of hiring.

Note that monetary policy shocks have very little persistence, even with the interest rate smoothing in the Taylor rule which we have assumed. So it is natural to investigate the robustness of these results in the case whereby monetary policy shocks display effects beyond the first quarter. We achieve this by assuming autocorrelated monetary policy shocks without interest rate smoothing (using $\rho_{\tilde{\xi}}=0.5$ and $\rho_{r}=0$ ), as in Galí (2011). This is shown in panel $\mathrm{b}$ of Figure B2. This alternative parameterization reproduces about the same autocorrelation of marginal costs as in Galí (2011, Figure 4a).

\section{Figure B2b}

\footnotetext{
${ }^{25}$ These effects do not last for long, as the model lacks propagation. More on this below, when discussing Figure B2b.
} 
In this case the model with all the frictions generates some real effects of monetary policy shocks, particularly through the response of investment, as the response of hiring is muted. However, the responses of output, employment and capital in the NK model with hiring frictions are small and substantially close to those of the NC benchmark.

We also notice that the response of real wages in both Figures B2a and B2b is smoothed when hiring frictions are introduced into the baseline NK model. Hence, in analogy with the case of technology shocks, hiring frictions generate endogenous real wage rigidity.

To sum up, the qualitative effect of hiring frictions in Figure B2b is again to bring the outcomes of the model with both frictions (green line) closer to the frictionless NC case (black line).

We conclude that hiring frictions matter substantially in the transmission of both technology and monetary policy shocks. Specifically, these frictions offset the impact of price frictions on the propagation of shocks. 


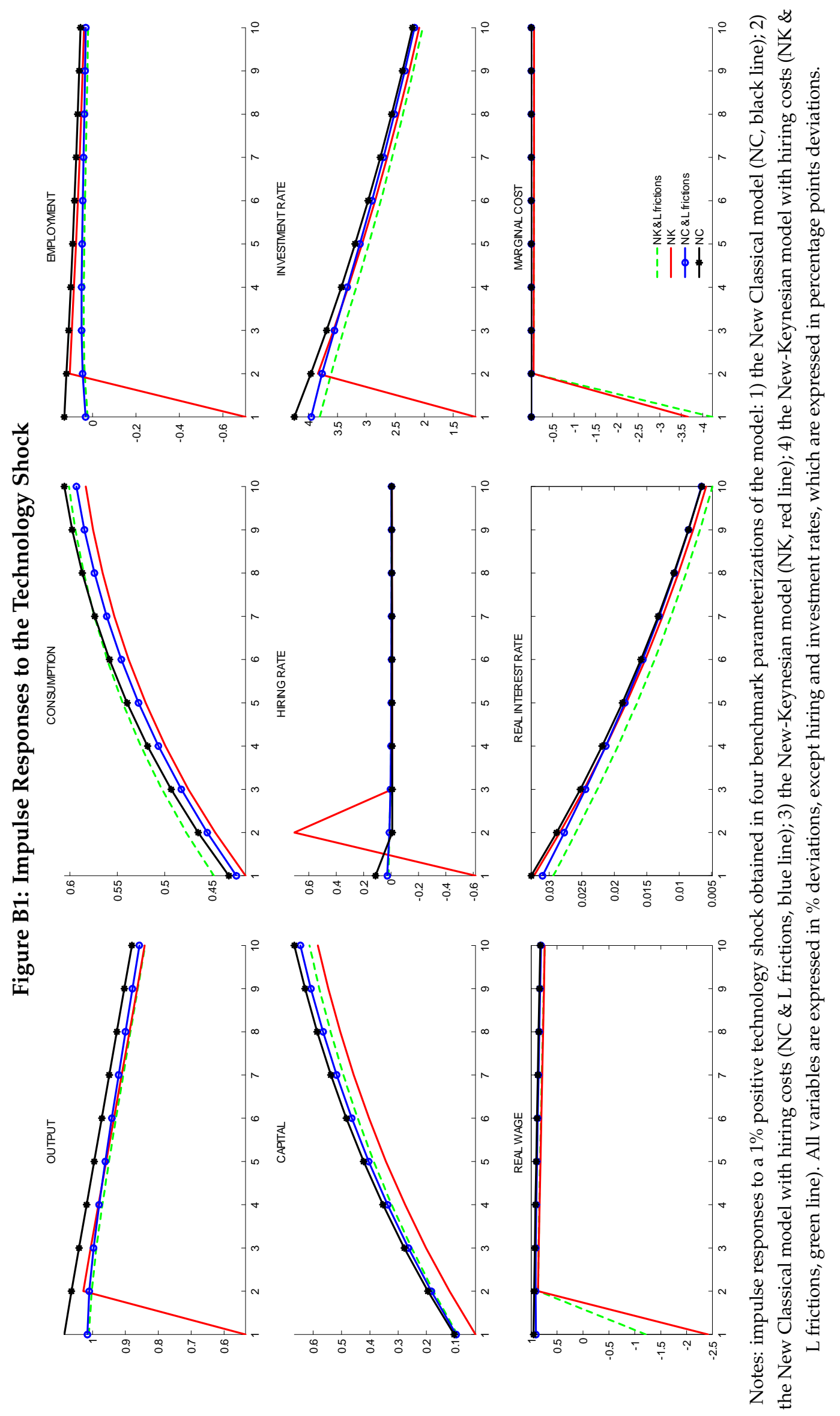




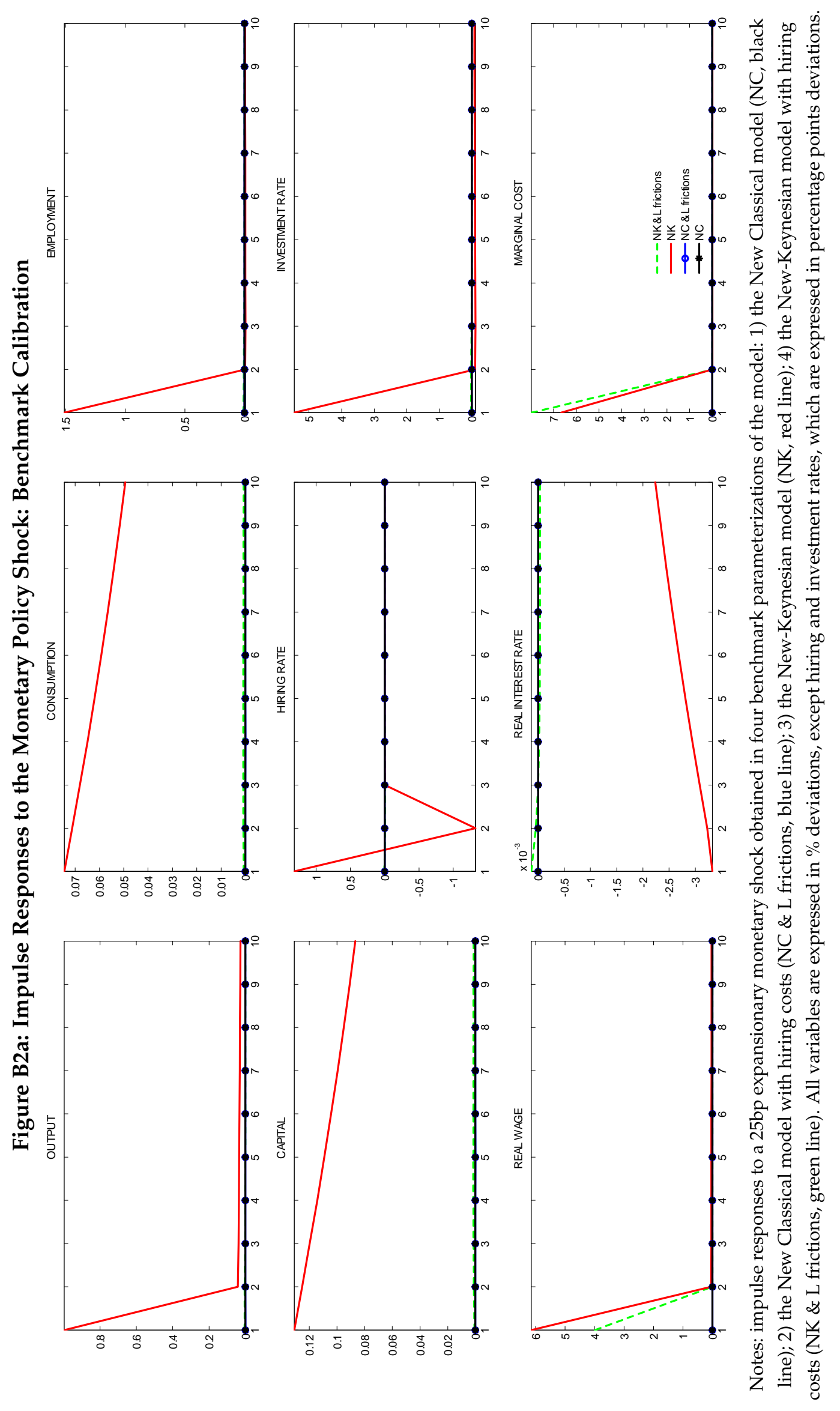




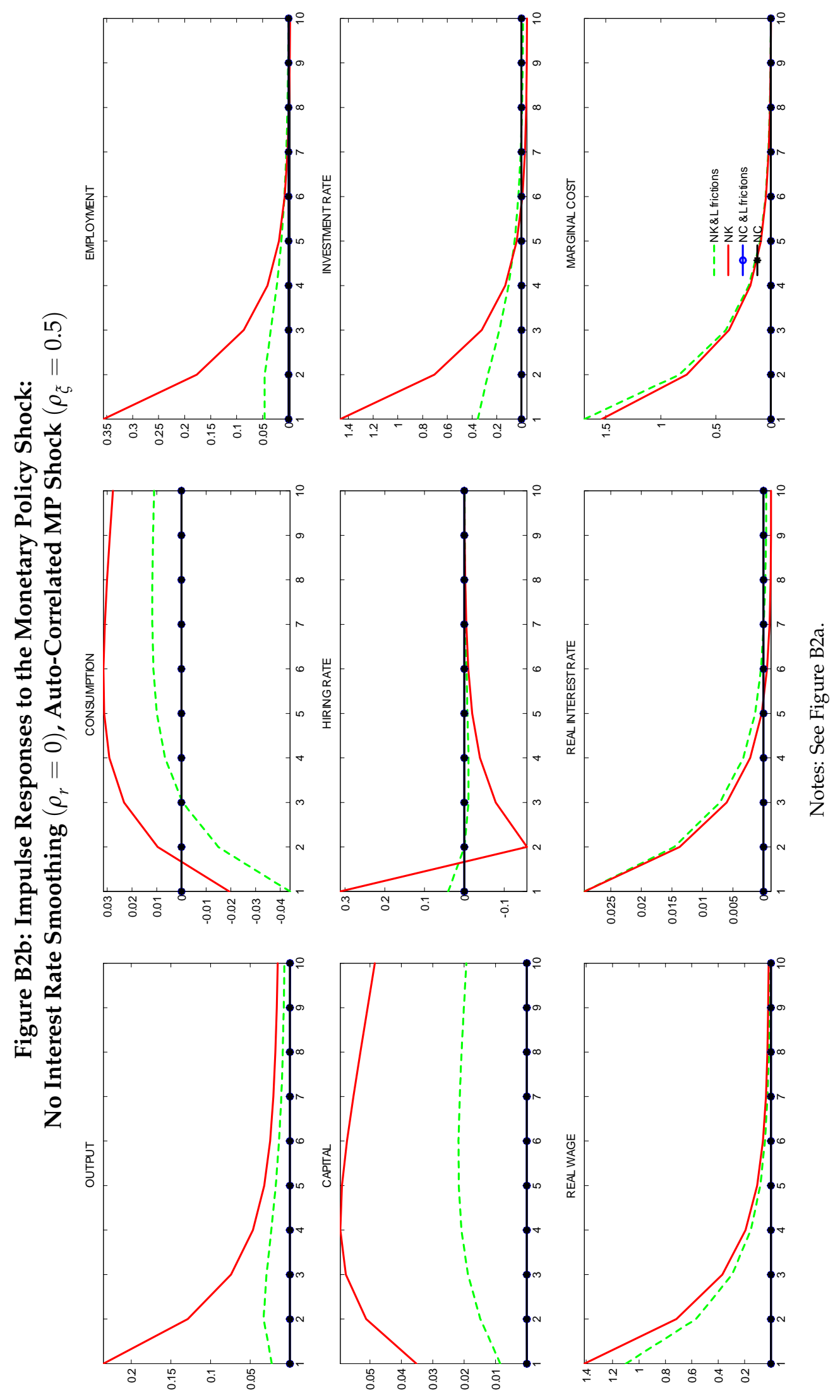




\section{Appendix C}

\section{The Extended Model}

This Appendix characterizes the extended model used to derive the results reported in Figures 3 to 8 . The model augments the simple set-up of Section 3 to specifically include a matching function in the labor market, external habits in consumption and investment adjustment costs to the problem of the households, external hiring costs, trend inflation and inflation indexation in the problem of the intermediate firms, and exogenous wage rigidity in the wage rule.

\section{Households}

Let $\vartheta \in[0,1)$ be the parameter governing external habit formation. The intertemporal problem of a household indexed by subscript $j$ is to maximize the discounted present value of current and future utility:

$$
\max _{\left\{C_{t+s, j}, I_{t+s, j}, B_{t+s+1, j}\right\}_{s=0}^{\infty}} E_{t} \sum_{s=0}^{\infty} \beta^{s}\left[\ln \left(C_{t+s, j}-\vartheta C_{t+s-1}\right)-\frac{\chi}{1+\varphi} N_{t+s, j}^{1+\varphi}\right],
$$

subject to the budget constraint (2) and the laws of motion for employment (3) and capital:

$$
K_{t, j}=\left(1-\delta_{K}\right) K_{t-1, j}+\left[1-S\left(\frac{I_{t, j}}{I_{t-1, j}}\right)\right] I_{t, j}, \quad 0 \leq \delta_{K} \leq 1,
$$

where $S$ is the investment adjustment cost function. It is assumed that $S(1)=S^{\prime}(1)=0$, and $S^{\prime \prime}(1) \equiv \phi>0$. Denoting by $\lambda_{t}$ the Lagrange multiplier associated with the budget constraint, and by $Q_{t}^{K}$ the Lagrange multiplier associated with the law of motion for capital, under the assumption that all households are identical in equilibrium, the conditions for dynamic optimality are:

$$
\begin{gathered}
\lambda_{t}=\frac{1}{P_{t}\left(C_{t}-\vartheta C_{t-1}\right)}, \\
\frac{1}{R_{t}}=\beta E_{t} \frac{\lambda_{t+1}}{\lambda_{t}}, \\
Q_{t}^{K}=E_{t} \Lambda_{t, t+1}\left[\frac{R_{t+1}^{K}}{P_{t+1}}+\left(1-\delta_{K}\right) Q_{t+1}^{K}\right] \\
V_{t}^{N}=\frac{W_{t}}{P_{t}}-\frac{\chi N_{t}^{\varphi}}{\lambda_{t} P_{t}}-\frac{x_{t}}{1-x_{t}} V_{t}^{N}+E_{t} \Lambda_{t, t+1}\left(1-\delta_{N}\right) V_{t+1}^{N},
\end{gathered}
$$

and

$$
Q_{t}^{K}\left[1-S\left(\frac{I_{t}}{I_{t-1}}\right)-S^{\prime}\left(\frac{I_{t}}{I_{t-1}}\right) \frac{I_{t}}{I_{t-1}}\right]+E_{t} \Lambda_{t, t+1} Q_{t+1}^{K} S^{\prime}\left(\frac{I_{t+1}}{I_{t}}\right)\left(\frac{I_{t+1}}{I_{t}}\right)^{2}=1,
$$

where the Euler equation (59), the value of capital (6), and the value of a marginal job to the household (61) correspond to equations (5), (20) and (7) in the simple model of Section 3, respectively. 


\section{Intermediate Firms}

We assume price stickiness à la Rotemberg (1982), meaning firms maximize current and expected discounted profits subject to quadratic price adjustment costs. We assume that adjustment costs depend on the ratio between the new reset price and the one set in the previous period, adjusted by a geometric average of gross steady state inflation, $1+\bar{\pi}$, and past inflation. We denote by $\psi$ the parameter that captures the degree of indexation to past inflation.

Firms maximize the following expression:

$$
\begin{aligned}
& \max _{\left\{P_{t+s, i}, H_{t+s, i} \breve{K}_{t+s, i}\right\}} E_{t} \sum_{s=0}^{\infty} \Lambda_{t, t+s}\left\{\frac{P_{t+s, i}}{P_{t+s}} Y_{t+s, i}-\frac{W_{t+s, i}}{P_{t+s}} N_{t+s, i}-\frac{R_{t+s}^{K}}{P_{t+s}} \breve{K}_{t+s, i}\right. \\
&\left.-\frac{\zeta}{2}\left(\frac{P_{t+s, i}}{\left(1+\pi_{t+s-1}\right)^{\psi}(1+\bar{\pi})^{1-\psi} P_{t+s-1, i}}-1\right)^{2} Y_{t+s}\right\}
\end{aligned}
$$

where $\Lambda_{t, t+s}=\beta^{s} \frac{C_{t}}{C_{t+s}}$ is the real discount factor of the households who own the firms, taking as given the demand function (10) and subject to the law of motion for employment (11) and the constraint that output equals demand:

$$
\left(\frac{P_{t, i}}{P_{t}}\right)^{-\epsilon} Y_{t}=f\left(A_{t}, N_{t, i} \breve{K}_{t, i}\right)-g\left(A_{t}, H_{t, i}, N_{t, i}, \breve{K}_{t, i}\right)
$$

The friction cost function in the above constraint is given by

$$
g\left(A_{t}, H_{t, i}, N_{t, i}, \breve{K}_{t, i}\right)=\frac{e}{2} q_{t}^{-\eta^{q}}\left(\frac{H_{t, i}}{N_{t, i}}\right)^{2} f_{t, i}
$$

where $V_{t}$ are aggregate vacancies and $q_{t}=\frac{H_{t}}{V_{t}}$ is the vacancy filling rate implied by the matching function in eq.(35).

Following a similar argument to the one proposed by Gertler, Sala and Trigari (2008), we note that by choosing vacancies, the firm directly controls the total number of hires $H_{t, i}=q_{t} V_{t, i}$, since it knows the vacancy filling rate $q_{t}$. Hence, $H_{t, i}$ can be treated as a control variable.

The optimality conditions with respect to $H_{t, i}, N_{t, i}, \breve{K}_{t, i}$ and $P_{t, i}$ are:

$$
\begin{gathered}
Q_{t}^{N}=\Psi_{t} g_{H, t}, \\
Q_{t}^{N}=\Psi_{t}\left(f_{N, t}-g_{N, t}\right)-\frac{W_{t}}{P_{t}}+\left(1-\delta_{N}\right) E_{t} \Lambda_{t, t+1} Q_{t+1}^{N}, \\
\frac{R_{t}^{K}}{P_{t}}=\Psi_{t}\left(f_{K, t}-g_{K, t}\right)
\end{gathered}
$$


and

$$
\begin{gathered}
(1-\epsilon)\left(\frac{P_{t, i}}{P_{t}}\right)^{-\epsilon} \frac{Y_{t}}{P_{t}}+\Psi_{t} \epsilon\left(\frac{P_{t, i}}{P_{t}}\right)^{-\epsilon-1} \frac{Y_{t}}{P_{t}} \\
-\zeta\left(\frac{P_{t, i}}{\left(1+\pi_{t-1}\right)^{\psi}(1+\bar{\pi})^{1-\psi} P_{t-1, i}}-1\right) \frac{Y_{t}}{\left(1+\pi_{t-1}\right)^{\psi}(1+\bar{\pi})^{1-\psi} P_{t-1, i}} \\
+E_{t} \Lambda_{t, t+1} \zeta\left(\frac{P_{t+1, i}}{(1+\pi)^{\psi}(1+\bar{\pi})^{1-\psi} P_{t, i}}-1\right) Y_{t+1}\left(\frac{P_{t+1, i}}{\left(\left(1+\pi_{t-1}\right)^{\psi}(1+\bar{\pi})^{1-\psi} P_{t, i}\right)^{2}}\right)=0 .
\end{gathered}
$$

Since all firms set the same price and therefore produce the same output in equilibrium, the above equation can be rearranged as follows:

$$
\begin{gathered}
\left(\frac{1+\pi_{t}}{\left(1+\pi_{t-1}\right)^{\psi}(1+\bar{\pi})^{1-\psi}}-1\right) \frac{1+\pi_{t}}{\left(1+\pi_{t-1}\right)^{\psi}(1+\bar{\pi})^{1-\psi}}=\frac{1-\epsilon}{\zeta}+\frac{\epsilon}{\zeta} \Psi_{t} \\
+E_{t} \frac{1}{R_{t} /\left(1+\pi_{t+1}\right)}\left[\left(\frac{1+\pi_{t+1}}{\left(1+\pi_{t}\right)^{\psi}(1+\bar{\pi})^{1-\psi}}-1\right) \frac{1+\pi_{t+1}}{\left(1+\pi_{t}\right)^{\psi}(1+\bar{\pi})^{1-\psi}} \frac{Y_{t+1}}{Y_{t}}\right] .
\end{gathered}
$$

Merging the FOCs for capital of households and firms (60) and (68) we get:

$$
Q_{t}^{K}=E_{t} \Lambda_{t, t+1}\left[\Psi_{t+1}\left(f_{K, t+1}-g_{K, t+1}\right)+\left(1-\delta_{K}\right) Q_{t+1}^{K}\right]
$$

Wage norm

We assume wage rigidity in the form of a Hall (2005) type wage norm:

$$
\frac{W_{t}}{P_{t}}=\omega \frac{W_{t-1}}{P_{t-1}}+(1-\omega) \frac{W_{t}^{N A S H}}{P_{t}}
$$

where $\omega$ is a parameter governing real wage stickiness, and $W_{t}^{N A S H}$ denotes the Nash reference wage

$$
W_{t}^{N A S H}=\arg \max \left\{\left(V_{t}^{N}\right)^{\gamma}\left(Q_{t}^{N}\right)^{1-\gamma}\right\}
$$

Final good firms

Final firms maximize

$$
\max P_{t} Y_{t}-\int_{0}^{1} P_{i, t} Y_{i, t} d i
$$


subject to

$$
Y_{t}=\left(\int_{0}^{1} Y_{t, i}{ }^{(\epsilon-1) / \epsilon} d i\right)^{\epsilon /(\epsilon-1)} .
$$

Taking first order conditions with respect to $Y_{t}$ and $Y_{i t}$ and merging we can solve for the demand function

$$
Y_{t, i}=\left(\frac{P_{t, i}}{P_{t}}\right)^{-\epsilon} Y_{t}
$$

The Monetary and Fiscal Authorities and Market Clearing

The model is closed by assuming that the government runs a balanced budget, as per eq. (26), the monetary authority follows the Taylor rule in eq.(27), the goods market clears as per eq.(28) and the capital market clears, $\breve{K}_{t}=K_{t-1}$. 
Table 1: Calibrated Parameters and Steady State Values, Baseline Model

\begin{tabular}{lll}
\hline Description & Parameter & Value \\
\hline Discount factor & $\beta$ & 0.99 \\
Separation rate & $\delta_{N}$ & 0.126 \\
Capital depreciation rate & $\delta_{K}$ & 0.024 \\
Elasticity of output to labor input & $\alpha$ & 0.66 \\
Hiring frictions scale parameter & $e$ & 1.5 \\
Elasticity of substitution & $\epsilon$ & 11 \\
Workers' bargaining power & $\gamma$ & 0.29 \\
Scale parameter in utility function & $\chi$ & 1 \\
Inverse Frisch elasticity & $\varphi$ & 4 \\
Price frictions (Rotemberg) & $\zeta$ & 120 \\
Taylor rule coefficient on inflation & $r_{\pi}$ & 1.5 \\
Taylor rule coefficient on output & $r_{y}$ & 0.125 \\
Taylor rule smoothing parameter & $\rho_{r}$ & 0.75 \\
Autocorrelation technology shock & $\rho_{a}$ & 0.95 \\
Autocorrelation monetary shock & $\rho_{\xi}$ & 0 \\
\hline Panel B: Steady State Values & & \\
\hline Definition & $E x p r e s s i o n$ & Value \\
Total adjustment cost/ output & $g /(f-g)$ & 0.012 \\
Marginal hiring cost & $g_{H} /[(f-g) / N]$ & 0.20 \\
Opportunity cost of work/ marginal revenue prod. & $\chi \frac{\chi C N^{\varphi}}{m c\left(f_{N}-g_{N}\right)}$ & 0.77 \\
Unemployment rate & $u$ & 0.106 \\
\hline \hline
\end{tabular}


Table 2: Calibrated Parameters and Steady State Values, Extended Model

\begin{tabular}{|c|c|c|}
\hline Description & Parameter & Value \\
\hline Discount factor & $\beta$ & 0.9978 \\
\hline Separation rate & $\delta_{N}$ & 0.126 \\
\hline Capital depreciation rate & $\delta_{K}$ & 0.024 \\
\hline Elasticity of output to labor input & $\alpha$ & 0.66 \\
\hline Hiring friction scale parameter & $e$ & 1.85 \\
\hline Elasticity of hiring costs to vacancy filling rate & $\eta^{q}$ & 0.49 \\
\hline Elasticity of substitution & $\epsilon$ & 11 \\
\hline Workers' bargaining power & $\gamma$ & 0.36 \\
\hline Scale parameter in utility function & $\chi$ & 5.84 \\
\hline Inverse Frisch elasticity & $\varphi$ & 4 \\
\hline Matching function parameter & $l$ & 1.39 \\
\hline Price frictions (Rotemberg) & $\zeta$ & 120 \\
\hline External habits & $\vartheta$ & 0.8 \\
\hline Exogenous wage rigidity & $\omega$ & 0.8 \\
\hline Investment adjustment costs & $\phi$ & 2.5 \\
\hline Trend inflation & $\bar{\pi}$ & 0.783 \\
\hline Inflation indexation & $\psi$ & 0.5 \\
\hline Taylor rule coefficient on inflation & $r_{\pi}$ & 1.5 \\
\hline Taylor rule coefficient on output & $r_{y}$ & 0.125 \\
\hline Taylor rule smoothing parameter & $\rho_{r}$ & 0.75 \\
\hline Autocorrelation technology shock & $\rho_{a}$ & 0.95 \\
\hline Autocorrelation monetary shock & $\rho_{\xi}$ & 0 \\
\hline \multicolumn{3}{|l|}{ Panel B: Steady State Values } \\
\hline Definition & Expression & Value \\
\hline Total adjustment cost/ output & $g /(f-g)$ & 0.012 \\
\hline Marginal hiring cost & $g_{H} /[(f-g) / N]$ & 0.20 \\
\hline Opportunity cost of work/ marginal revenue prod. & $\frac{\chi C N^{\varphi}}{m c\left(f_{N}-g_{N}\right)}$ & 0.77 \\
\hline Vacancy filling rate & $q$ & 0.7 \\
\hline Unemployment rate & $u$ & 0.106 \\
\hline
\end{tabular}




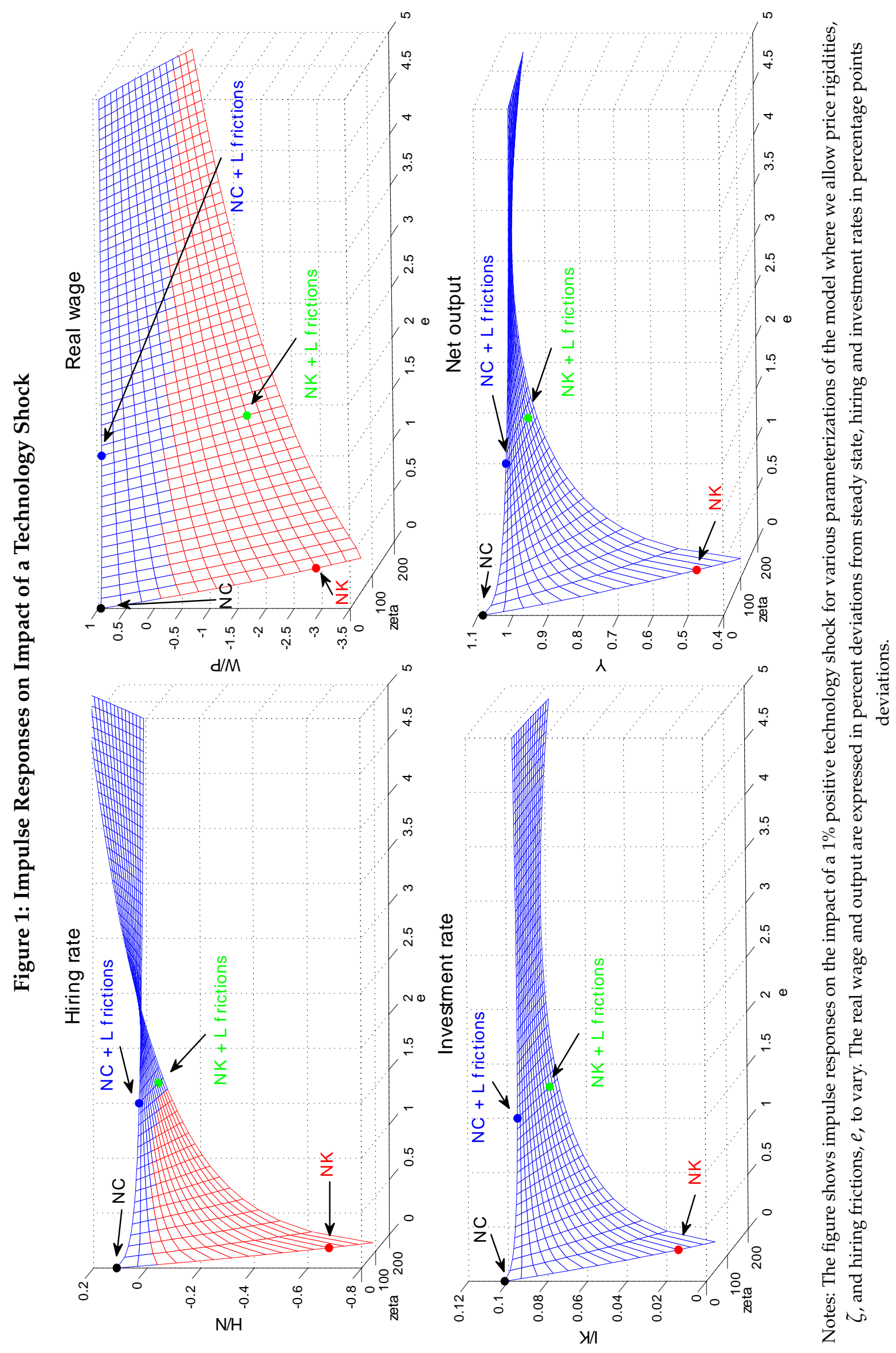



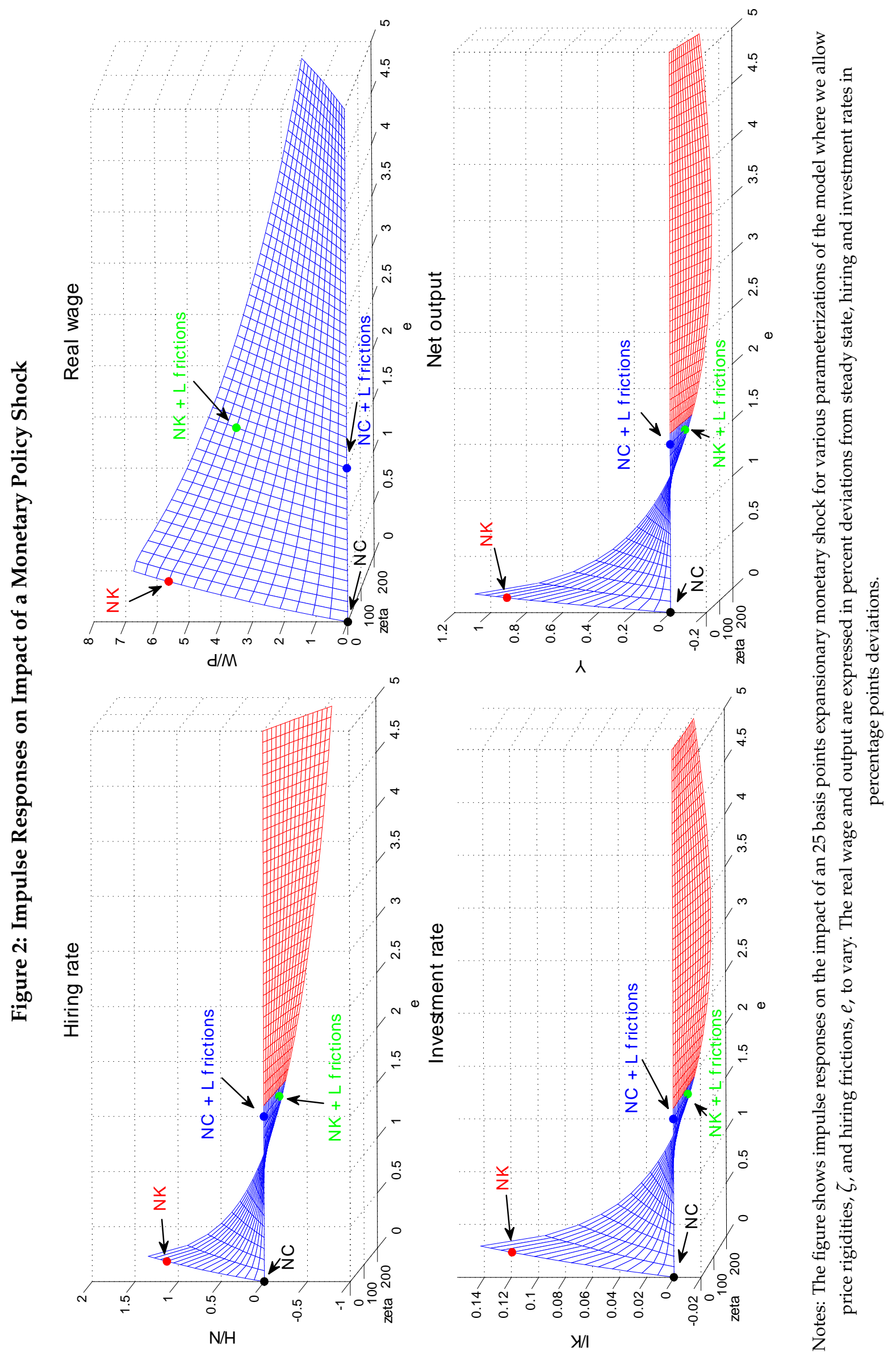

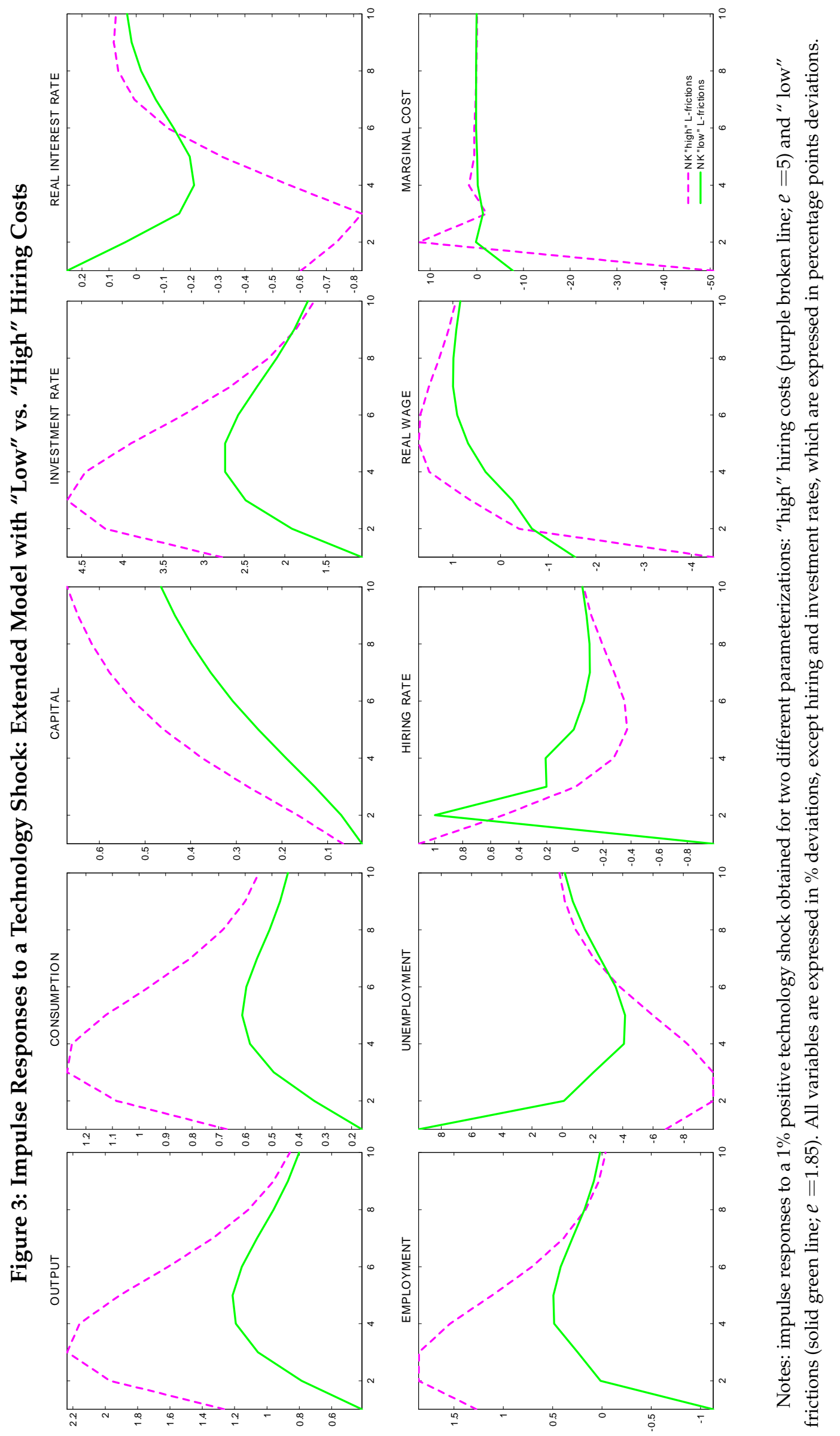

อี ฐ

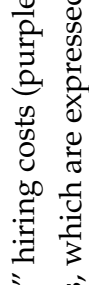

迎

苑 范

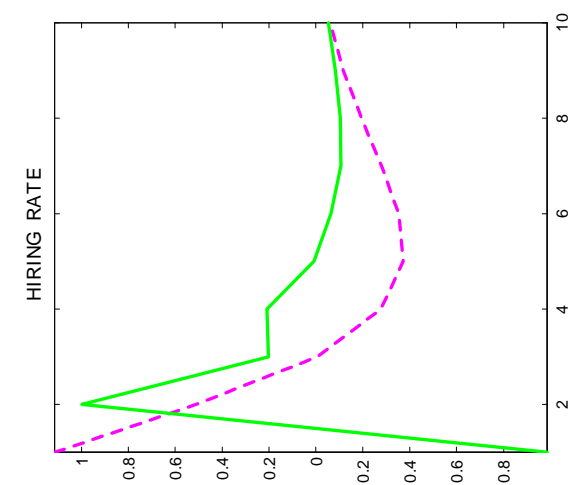

荧

可

है

胥

离

క.

प्र

坖

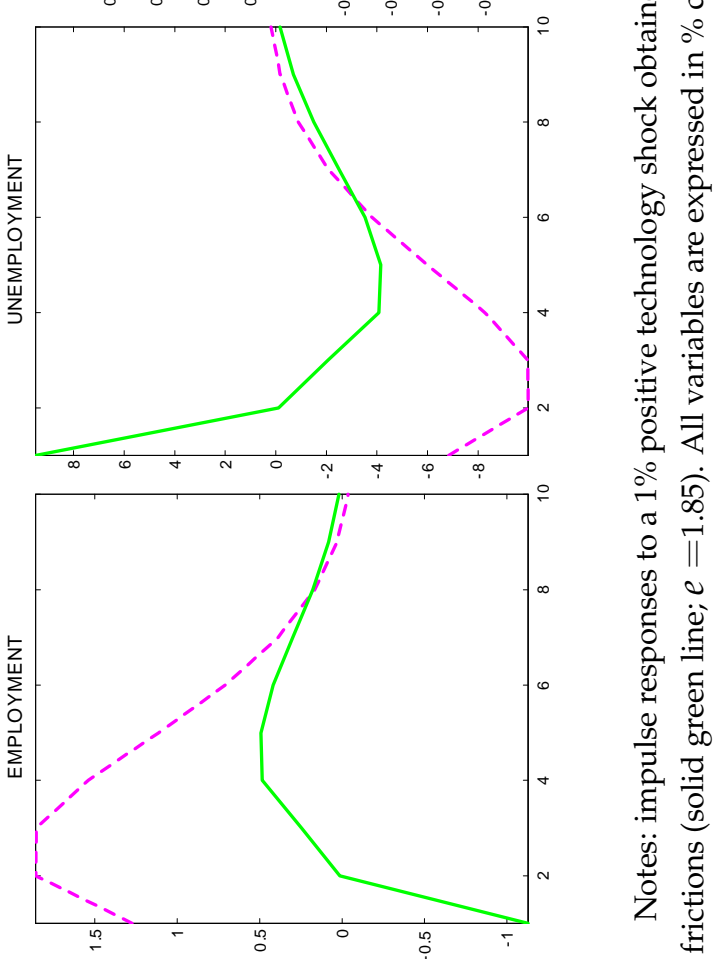




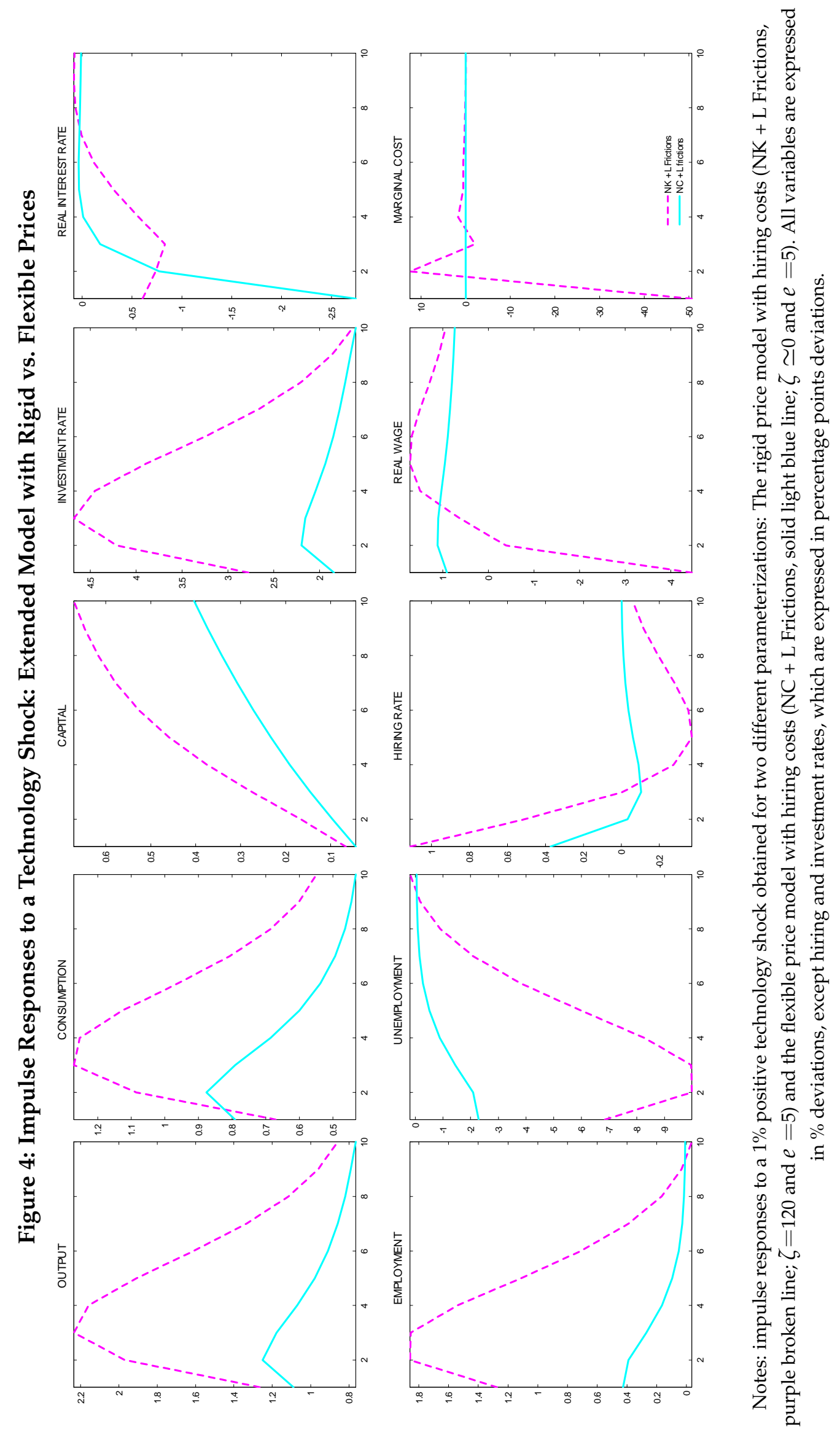



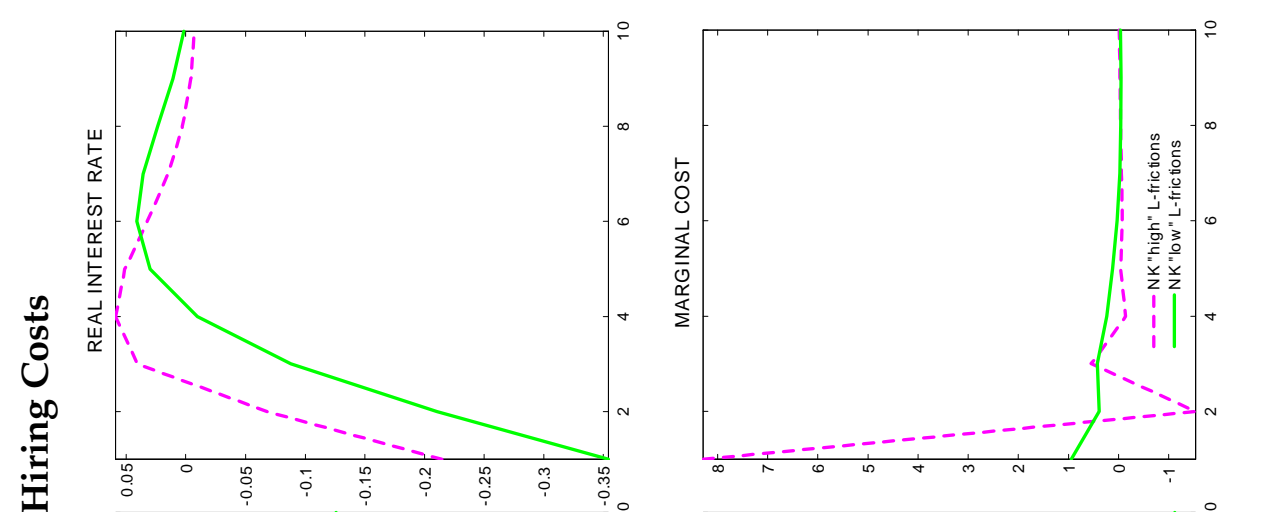

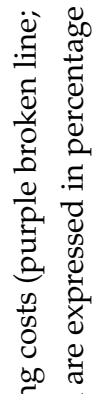
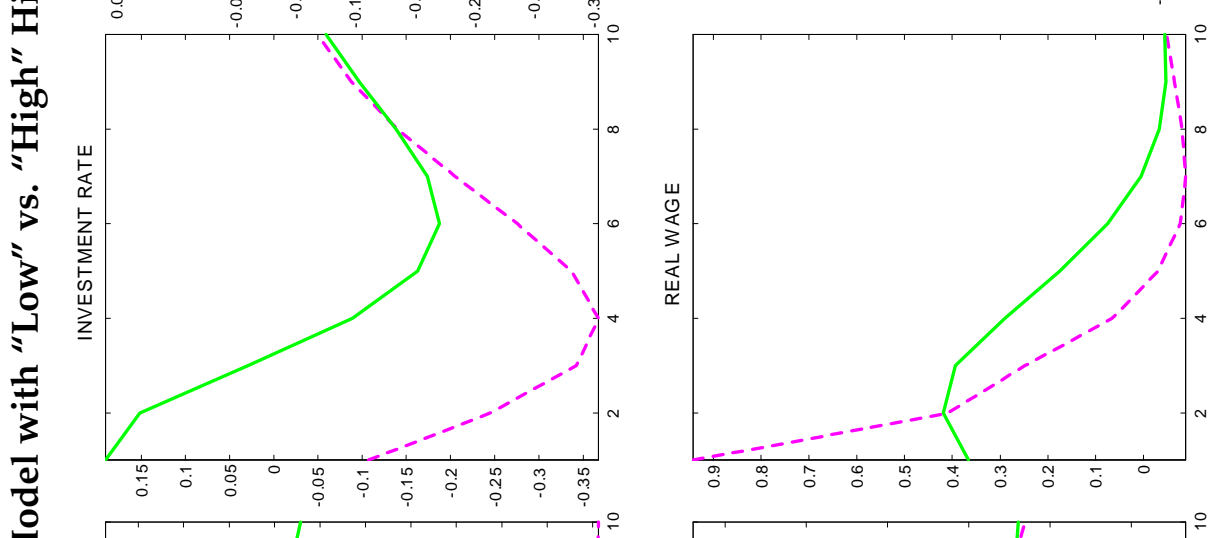

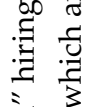

造步

:

.

ญ.

छ్ స్త్ర

ฉ.

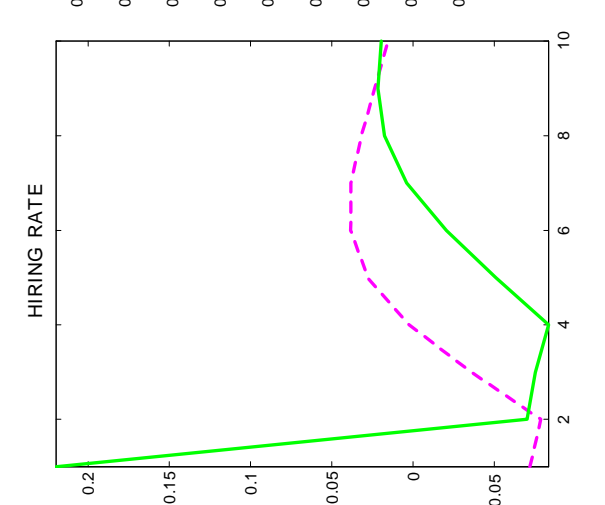

这
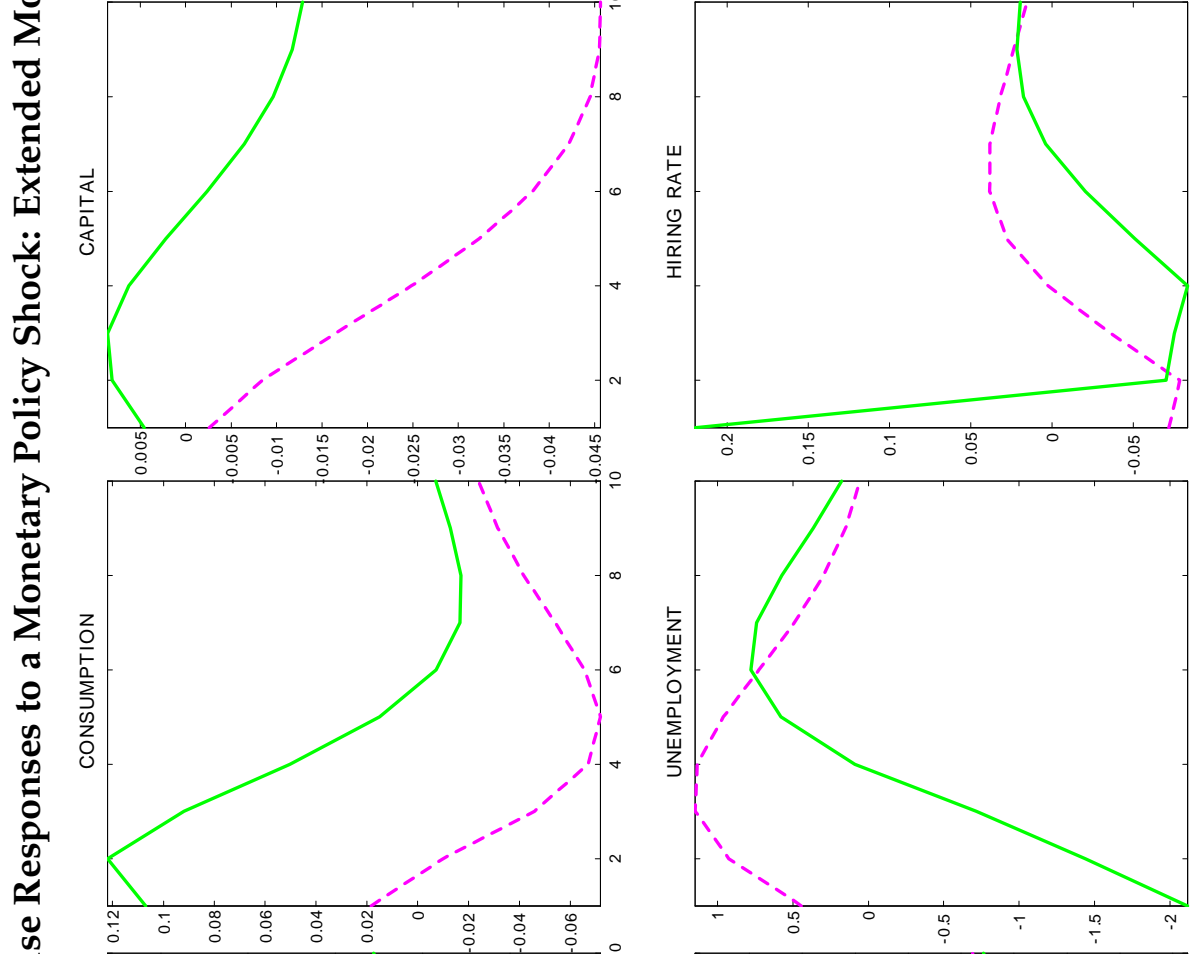

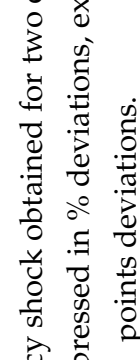

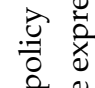

है

敋娄

ฮี

常京

它官

爻

节苛

离

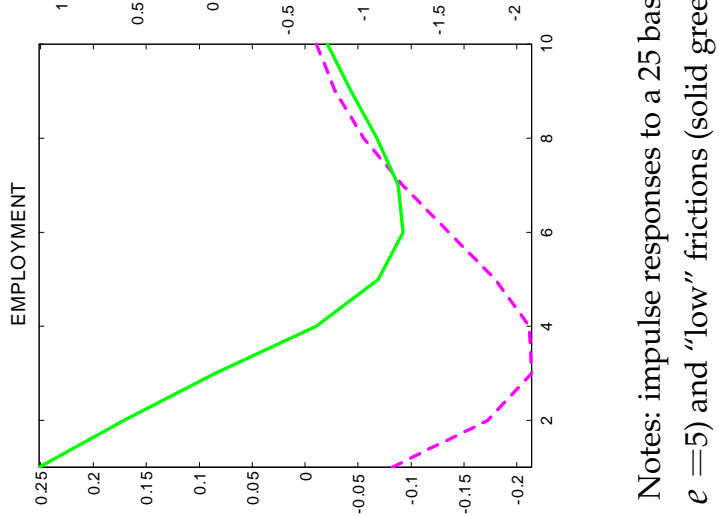




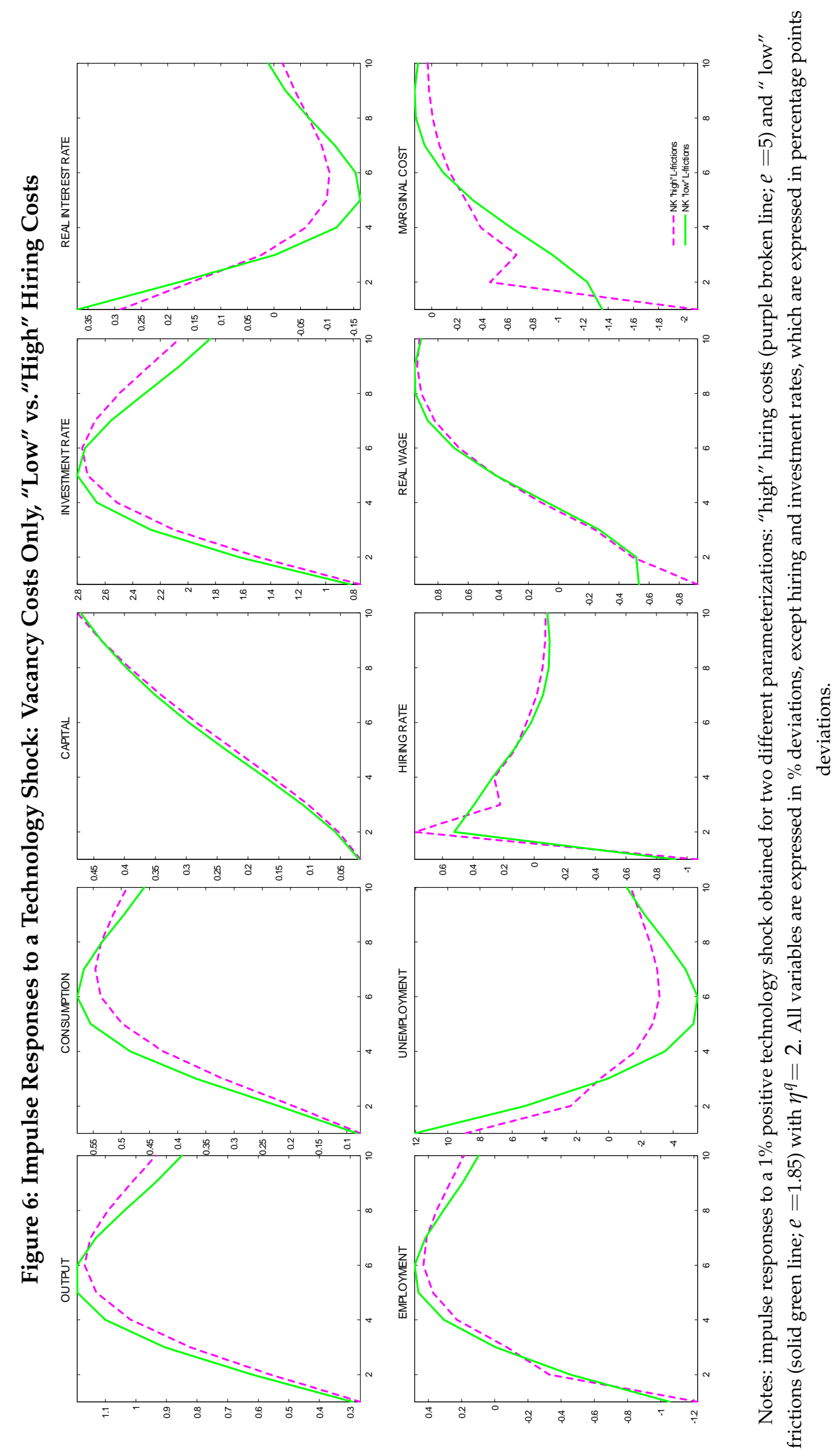




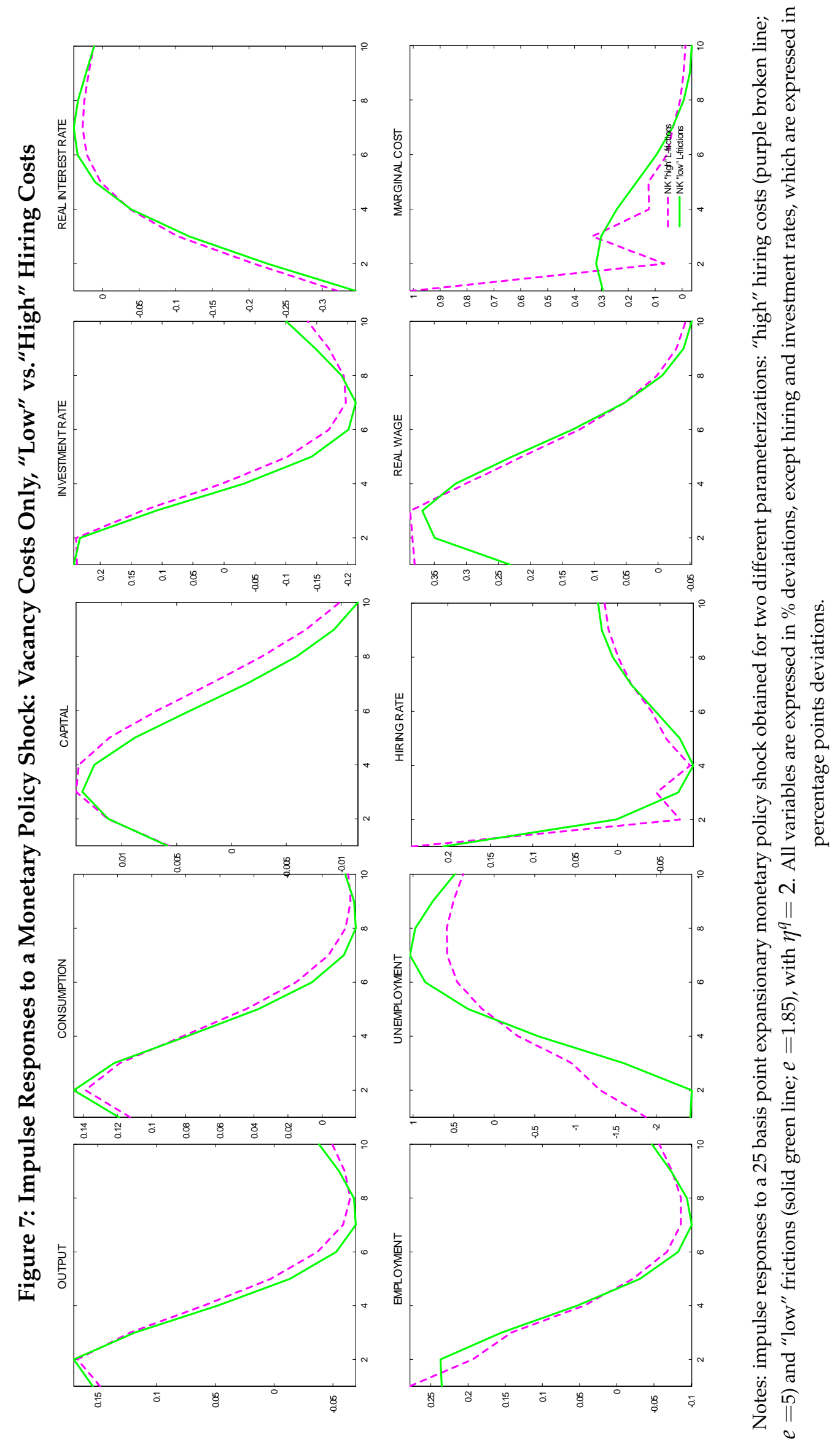

